\title{
Oligomerization and Phase Transitions in Aqueous Solutions of Native and Truncated Human $\beta$ B1-Crystallin ${ }^{\dagger}$
}

\author{
Onofrio Annunziata, ${ }^{\ddagger} \S$ Ajay Pande, ${ }^{\S}$ Jayanti Pande, ${ }^{\S}$ Olutayo Ogun, ${ }^{\S}$ Nicolette H. Lubsen,, and \\ George B. Benedek*,§ \\ Department of Physics, Center for Materials Science and Engineering, and Materials Processing Center, \\ Massachusetts Institute of Technology, Cambridge, Massachusetts 02139, and Department of Biochemistry, \\ University of Nijmegen, $6500 \mathrm{HB}$ Nijmegen, The Netherlands
}

Received July 25, 2004; Revised Manuscript Received November 15, 2004

\begin{abstract}
Human $\beta \mathrm{B} 1$-crystallin is a major eye-lens protein that undergoes in vivo truncation at the $\mathrm{N}$-terminus with aging. By studying native $\beta \mathrm{B} 1$ and truncated $\beta \mathrm{B} 1 \Delta \mathrm{N} 41$, which mimics an age-related in vivo truncation, we have determined quantitatively the effect of truncation on the oligomerization and phase transition properties of $\beta \mathrm{B} 1$ aqueous solutions. The oligomerization studies show that the energy of attraction between the $\beta \mathrm{B} 1 \Delta \mathrm{N} 41$ proteins is about $10 \%$ greater than that of the $\beta \mathrm{B} 1$ proteins. We have found that $\beta \mathrm{B} 1 \Delta \mathrm{N} 41$ aqueous solutions undergo two distinct types of phase transitions. The first phase transition involves an initial formation of thin rodlike assemblies, which then evolve to form crystals. The induction time for the formation of rodlike assemblies is sensitive to oligomerization. The second phase transition can be described as liquid-liquid phase separation (LLPS) accompanied by gelation within the protein-rich phase. We refer to this process as heterogeneous gelation. These two phase transitions are not observed in the case of $\beta \mathrm{B} 1$ aqueous solutions. However, upon the addition of poly(ethylene glycol) (PEG), we observe heterogeneous gelation also for $\beta$ B 1. Our PEG experiments allow us to estimate the difference in phase separation temperatures between $\beta \mathrm{B} 1$ and $\beta \mathrm{B} 1 \Delta \mathrm{N} 41$. This difference is consistent with the increase in energy of attraction found in our oligomerization studies. Our work suggests that truncation is a cataractogenic modification since it favors protein condensation and the consequent formation of light scattering elements, and highlights the importance of the $\mathrm{N}$-terminus of $\beta \mathrm{B} 1$ in maintaining lens transparency.
\end{abstract}

Cataract is the opacification of the eye lens resulting in loss of vision. The opacification phenomenon is related to the presence of spatial inhomogeneities of the refractive index within the lens, which leads to light scattering $(1,2)$. Crystallins, which are the major structural proteins in the eye lens, are responsible for maintaining the spatial homogeneity of the refractive index. In the mammalian lenses, crystallins can be divided into three major classes: the $\alpha$-crystallins, which form large oligomers $(\approx 800 \mathrm{kDa})$; the $\beta$-crystallins, which form oligomers ranging from 50 to 200 $\mathrm{kDa}$; and the $\gamma$-crystallins, which remain monomers $(21 \mathrm{kDa})$ $(3,4)$.

The presence of protein-protein attractive interactions causes the formation of large protein clusters, which leads to the loss of refractive index homogeneity in the lens (1). The role of $\beta$-crystallins and their complex oligomerization process in relation to the refractive index properties of the lens is not well understood. Hence, it is clearly important to investigate $\beta$-crystallin oligomerization in solution.

\footnotetext{
This work was supported by National Institutes of Health Grants EY05127 and EY10535 and National Aeronautics and Space Administration Grant NAG8-1659.

* Corresponding author: Room 13-2005, Massachusetts Institute of Technology, 77 Massachusetts Ave., Cambridge, MA 02139-4307. Phone: (617) 253-4828. Fax: (617) 225-2585. E-mail: gbb@mit.edu.

Current address: Department of Chemistry, Texas Christian University, Fort Worth, TX 76129.

$\S$ Massachusetts Institute of Technology.

" University of Nijmegen.
}

Analysis by mass spectrometry has shown that there are six $\beta$-crystallins expressed in the human lens: $\beta \mathrm{A} 1, \beta \mathrm{A} 3$, $\beta \mathrm{A} 4, \beta \mathrm{B} 1,{ }^{1} \beta \mathrm{B} 2$, and $\beta \mathrm{B} 3(5-10)$. Size-exclusion chromatography shows that $\beta$-crystallins of human fetal lenses separate into two fractions of soluble hetero-oligomers: $\beta \mathrm{H}$ $(\approx 200 \mathrm{kDa})$ and $\beta \mathrm{L} 2(\approx 40 \mathrm{kDa})$. It was found that $\beta \mathrm{H}$ consists mainly of $\beta \mathrm{B} 1$ and $\beta \mathrm{A} 4$, while $\beta \mathrm{L} 2$ consists mainly of $\beta \mathrm{B} 2$ homodimers (10). An intermediate molecular weight fraction of hetero-oligomers, $\beta \mathrm{L} 1(\approx 80 \mathrm{kDa})$, appears after 1 year of age $(8-10)$. The $\beta$-crystallin subunits of the heterooligomers assemble by noncovalent specific interactions. Measurements of osmotic pressure and X-ray scattering show that the average interaction between hetero-oligomers is repulsive (11). Hence, hetero-oligomerization of $\beta$-crystallins appears to be protective against association and opacification $(11,12)$.

$\beta \mathrm{B} 1$ and $\beta \mathrm{B} 2$ are the only $\beta$-crystallins for which the threedimensional X-ray structure is available $(13,14)$. These two homologous proteins consist of two tightly packed globular domains that are linked by a connecting peptide. Each of these domains contains two Greek key motifs of antiparallel $\beta$-pleated sheets, analogous to the tertiary structure observed

\footnotetext{
${ }^{1}$ Abbreviations: $\beta \mathrm{B} 1$, human native $\beta \mathrm{B} 1$-crystallin; $\beta \mathrm{B} 1 \Delta \mathrm{N} 41$, human truncated $\beta \mathrm{B} 1$-crystallin missing 41 residues from the $\mathrm{N}$ terminus; $\mathrm{CD}$, circular dichroism; HPLC, high-pressure liquid chromatography; QLS, quasielastic light scattering; LLPS, liquid-liquid phase separation; PEG, poly(ethylene glycol); PEG1450, poly(ethylene glycol) with average molecular weight $1450 \mathrm{~g} / \mathrm{mol}$.
} 
in the case of $\gamma$-crystallins (15). Yet two main features distinguish the $\gamma$ and the $\beta$ families. On the basis of their crystal structures, $\gamma$-crystallins are monomers while both $\beta \mathrm{B} 1$ and $\beta \mathrm{B} 2$ are homodimers; the $\beta \mathrm{B} 1$ dimer is different from the $\beta \mathrm{B} 2$ dimer (13). These crystallographic findings are consistent with hydrodynamic $(10,16,17)$ and equilibrium $(18,19)$ measurements performed on these proteins in dilute aqueous solutions. Furthermore, both the $\mathrm{N}$ - and C-terminal peptide segments of the $\beta$-crystallins are projected outside the protein globular domains like extended arms $(4,10)$.

$\beta$ B1-Crystallin, which comprises $9 \%$ of the total crystallins in a newborn human lens $(5,9,20)$, undergoes extensive in vivo truncation of the $\mathrm{N}$-terminal arm. This degradation can delete as few as 15 and as many as 41 amino acids (6). Interestingly, it has been found that while the native $\beta \mathrm{B} 1$ is found in the $\beta \mathrm{H}$ oligomeric fraction, its truncated forms are found in the lower molecular weight oligomeric fractions, $\beta \mathrm{L} 1$ and $\beta \mathrm{L} 2$. This finding suggests that $\beta \mathrm{B} 1$ degradation causes the disassembly of several $\beta \mathrm{H}$ hetero-oligomers and a consequent redistribution of $\beta$-crystallins toward the low molecular weight fractions in aging lenses $(8,9)$. Thus the $\mathrm{N}$-terminal extension is believed to play a role in the formation of $\beta \mathrm{H}$ hetero-oligomer fraction $(8,21,22)$.

The oligomerization properties of both $\beta \mathrm{B} 1$ and $\beta \mathrm{B} 2$ have been studied in aqueous solutions (10). The most important results come from size-exclusion chromatography and quasielastic light scattering. The size of native $\beta \mathrm{B} 1$ and its truncated forms appeared to be highly concentration-dependent. On the other hand, the size of $\beta \mathrm{B} 2$ shows no significant concentration dependence. These observations indicate that $\beta \mathrm{B} 2$ remains a homodimer as its concentration increases. On the other hand, native $\beta \mathrm{B} 1$ and its truncated forms appear to undergo reversible homo-oligomerization. However, no quantitative comparison between native and truncated $\beta \mathrm{B} 1$ has been reported.

It might be expected that truncation of the $\mathrm{N}$-terminal of $\beta \mathrm{B} 1$ alters the conformational stability of the protein. However, circular dichroism and fluorescence studies on $\beta \mathrm{B} 1$ have shown that truncation does not affect the unfolding/ refolding properties of the protein (23).

Interestingly, aqueous solutions of $\beta \mathrm{B} 1$ with 41 amino acids deleted at the $\mathrm{N}$-terminus $(\beta \mathrm{B} 1 \Delta \mathrm{N} 41)$, which mimics an age-related in vivo truncation, undergo reversible opacification on cooling below $4{ }^{\circ} \mathrm{C}(10)$. A similar type of phenomenon, related to the onset of a liquid-liquid phase transition, has been reported for $\gamma$-crystallin aqueous solutions $(24-31)$. This phase transition has been associated with the existence of protein-protein attractive interactions and thus is directly relevant to the refractive index properties of the eye lens and cataract formation. It is important to point out that $\gamma$-crystallins, in contrast with $\beta \mathrm{B} 1 \Delta \mathrm{N} 41$, do not undergo reversible oligomerization in solution $(11,16,31)$.

The first goal of this paper is to determine quantitatively the effect of truncation on the oligomerization and phase transition properties of $\beta \mathrm{B} 1$ aqueous solutions. The second goal is to compare the phase behavior for $\beta \mathrm{B} 1$-crystallin with that of the well-characterized $\gamma$-crystallin systems. This work provides important insights on the effect of reversible oligomerization on the phase transitions of protein solutions.

We use recombinant DNA techniques to produce native $\beta \mathrm{B} 1$ and truncated $\beta \mathrm{B} 1 \Delta \mathrm{N} 41$. We first analyze the effect of truncation on the structural properties of the individual proteins by comparing the circular dichroism and hydrodynamic properties of $\beta \mathrm{B} 1$ and $\beta \mathrm{B} 1 \Delta \mathrm{N} 41$ in solution. Second, we study, by quasielastic light scattering, the oligomerization of both $\beta \mathrm{B} 1$ and $\beta \mathrm{B} 1 \Delta \mathrm{N} 41$ so as to assess the role of the $\mathrm{N}$-terminal arm. Third, in the case of aqueous solutions of truncated $\beta \mathrm{B} 1 \Delta \mathrm{N} 41$, we investigate the phase transitions and compare them with those of $\gamma$-crystallin solutions. We also establish that phase separation for native $\beta \mathrm{B} 1$ aqueous solutions is not observed. In this case, phase separation can be induced by adding poly(ethylene glycol) (PEG). Finally, we discuss our findings in relation to eye-lens transparency.

\section{MATERIALS AND METHODS}

Expression, Purification, and Characterization of Human $\beta B 1$ and $\beta B 1 \triangle N 41$. Recombinant human $\beta$ B1-crystallin $(\beta \mathrm{B} 1)$ and its truncated form $(\beta \mathrm{B} 1 \Delta \mathrm{N} 41)$ were expressed in Escherichia coli. The expression plasmids were obtained as described by Bateman et al. (10). The pET3a recombinant plasmids were transformed into BL21(DE3) GOLD cells (Stratagene). For the overexpression of $\beta \mathrm{B} 1$ and $\beta \mathrm{B} 1 \Delta \mathrm{N} 41$, the bacterial cultures were grown at $37^{\circ} \mathrm{C}$ to an absorbance at $600 \mathrm{~nm}\left(A_{600}\right)$ of about 0.5. Expression of $\beta \mathrm{B} 1$ and $\beta \mathrm{B} 1 \Delta \mathrm{N} 41$ was induced by the addition of isopropyl 1-thioD-galactopyranoside to a final concentration of about $1 \mathrm{mM}$, and the cultures were grown for an additional 5-6 h. Cells were pelleted by centrifugation, and the pellet was resuspended in lysis buffer $(50 \mathrm{mM}$ Tris $\cdot \mathrm{HCl}$ containing $25 \mathrm{mM}$ $\mathrm{NaCl}$ and $2 \mathrm{mM}$ EDTA, $\mathrm{pH}$ 8), to which complete protease inhibitor (Roche Molecular Biochemicals) was added at 1 tablet per $30 \mathrm{~mL}$. The cell suspension was lysed with lysozyme $(250 \mu \mathrm{g} / \mathrm{mL})$ followed by five cycles of a rapid freeze-thaw procedure that involved freezing in liquid nitrogen followed by thawing in a water bath set at $30{ }^{\circ} \mathrm{C}$. To this suspension, DNase $(1 \mathrm{mg} / \mathrm{mL})$ was added, followed by centrifugation at $48400 \mathrm{~g}$. Both the supernatant and pellet were tested for the presence of crystallins by SDS-PAGE. The $\beta$-crystallins fractionated almost exclusively ( $>95 \%)$ into the supernatant. In the case of $\beta \mathrm{B} 1$, the supernatant was dialyzed exhaustively into $10 \mathrm{mM}$ phosphate buffer at $\mathrm{pH}$ 7.0. In the case of $\beta \mathrm{B} 1 \Delta \mathrm{N} 41$, the supernatant was dialyzed exhaustively into $10 \mathrm{mM}$ phosphate buffer at $\mathrm{pH}$ 6.5. The dialyzed solutions were then loaded onto a size-exclusion Sepharose CL6B column and eluted with the same buffer. The fraction corresponding to the $\beta$-crystallins was then loaded onto a cation-exchange SP-Sepharose fast-flow column equilibrated with the corresponding buffer and eluted with a linear $\mathrm{NaCl}$ gradient increasing from 0 to $200 \mathrm{mM}$. The final product was analyzed by electrospray ionization mass spectrometry (performed at the Biopolymers Lab at the Center for Cancer Research at Massachusetts Institute of Technology, ESI-MS model LCQ, ThermoQuest, San Jose, CA), which confirmed the molecular masses of 27892 $\mathrm{g} / \mathrm{mol}$ for $\beta \mathrm{B} 1$ and $24192 \mathrm{~g} / \mathrm{mol}$ for $\beta \mathrm{B} 1 \Delta \mathrm{N} 41$.

Solution Preparation. The purified $\beta \mathrm{B} 1$ and $\beta \mathrm{B} 1 \Delta \mathrm{N} 41$ proteins were dialyzed exhaustively into sodium phosphate buffer $(0.1 \mathrm{M}, \mathrm{pH}$ 7.1) that contained sodium azide $(0.02 \%)$. Solutions containing dilute $\beta \mathrm{B} 1$ and $\beta \mathrm{B} 1 \Delta \mathrm{N} 41$ in phosphate buffer were concentrated by ultrafiltration (Amacon, $10 \mathrm{kDa}$ ) for low protein concentrations and centrifugation (Centricon, $10 \mathrm{kDa}$ ); centrifugation was used to reach high protein concentrations. The concentration of $\beta \mathrm{B} 1$ and $\beta \mathrm{B} 1 \Delta \mathrm{N} 41$ in 
the solutions were determined by UV absorption at $280 \mathrm{~nm}$ (after protein samples were diluted), using the extinction coefficient value of $2.05 \mathrm{mg}^{-1} \cdot \mathrm{mL} \cdot \mathrm{cm}^{-1}\left(5.70 \times 10^{4}\right.$ $\left.\mathrm{M}^{-1} \cdot \mathrm{cm}^{-1}\right)$ for $\beta \mathrm{B} 1$ and $2.36 \mathrm{mg}^{-1} \cdot \mathrm{mL} \cdot \mathrm{cm}^{-1}\left(5.70 \times 10^{4}\right.$ $\mathrm{M}^{-1} \cdot \mathrm{cm}^{-1}$ ) for $\beta \mathrm{B} 1 \Delta \mathrm{N} 41$ (www.expasy.ch). The linear dependence of the absorbance on the protein concentration was verified.

Poly(ethylene glycol) (PEG) with average molecular weight of $1450 \mathrm{~g} / \mathrm{mol}$ (PEG1450) was purchased from Sigma-Aldrich and used without further purification. ProteinPEG aqueous solutions were prepared as described elsewhere (30). The concentrations of PEG in solution are reported as weight percent.

Circular Dichroism. Circular dichroic (CD) spectra were obtained with an Aviv Associates spectrometer (model 202, Aviv Associates, Lakewood, NJ). Protein concentrations of $1 \mathrm{mg} / \mathrm{mL}$ in $0.1 \mathrm{M}$ phosphate buffer $(\mathrm{pH} 7.1)$ were used for near-UV CD spectra (range 260-340 nm, cell path length $1.0 \mathrm{~cm}$ ). Protein concentrations of $0.1 \mathrm{mg} / \mathrm{mL}$ in $0.01 \mathrm{M}$ phosphate buffer ( $\mathrm{pH}$ 7.1) were used for far-UV CD spectra (range 190-240 $\mathrm{nm}$, cell path length $0.1 \mathrm{~cm}$ ). The molar ellipticity, $[\theta]$, was reported.

Temperatures of unfolding were determined by measuring the $[\theta]$ value at $292 \mathrm{~nm}$ as a function of temperature. Starting from $20^{\circ} \mathrm{C}$, the temperature was increased at the rate of 0.4 ${ }^{\circ} \mathrm{C} / \mathrm{min}$ until protein precipitation, due to unfolding, was detected by the abrupt change of $[\theta]$.

Size-Exclusion High-Pressure Liquid Chromatography. Size-exclusion HPLC experiments were performed on a Superdex 75HR FPLC column (Amersham Pharmacia) at a flow rate of $1 \mathrm{~mL} / \mathrm{min}$. Proteins were eluted isocratically with $0.1 \mathrm{M}$ sodium phosphate buffer $(\mathrm{pH} 7.1)$ containing $0.02 \%$ sodium azide. The elution profiles indicate the presence of only one peak in both cases.

Quasielastic Light Scattering. All protein samples were filtered through a $0.02 \mu \mathrm{m}$ Millipore filter and placed in a test tube. Quasielastic light scattering (QLS) experiments were performed on a homemade light scattering apparatus by use of a PD2000DLS ${ }^{\text {PLUS }}$ correlator (256 channels; Precision Detectors, Bellingham, MA) and a Coherent $\mathrm{He}-$ Ne laser (35 mW, 632.8 nm; Coherent Radiation, Santa Clara, CA). The measurements were performed at a scattering angle of $90^{\circ}$. The sample holder temperature was controlled by a water bath. The actual temperature of the sample was measured (with a precision of $0.1{ }^{\circ} \mathrm{C}$ ) by placing a thermocouple close to the test tube containing the sample. The measured correlation functions were analyzed by the Precision Deconvolve 4.4 software provided by Precision Detectors. This software, which employs a constrained regularization method, is used to determine the scattered intensity versus the diffusion coefficient.

In all the experiments performed at temperatures higher than $6{ }^{\circ} \mathrm{C}$, the distribution of the scattering intensity was time-independent and clearly monomodal with a polydispersity index that was typically less than $20 \%$. The average deviation between the measured correlation function and the best fit was typically around $5 \times 10^{-5}$. The mean diffusion coefficient, $D$, was determined from the distribution. The mean apparent hydrodynamic radius, $R_{\mathrm{h}}{ }^{\text {app}}$, was calculated from $D$ by use of the Stokes-Einstein relation, $D=k_{\mathrm{B}} T /$ $6 \pi \eta R_{\mathrm{h}}{ }^{\text {app }}$, where $k_{\mathrm{B}}$ is Boltzmann's constant, $T$ is the absolute temperature, and $\eta$ is the solvent viscosity. The value of the viscosity of water at the temperature of the experiment was used for $\eta$.

For the experiments performed at $2.0{ }^{\circ} \mathrm{C}$, where the distribution of the scattered intensity was broad and timedependent, we report the normalized scattered intensity versus the apparent hydrodynamic radius as a function of time.

Phase Diagram. All protein samples were filtered through a $0.2 \mu \mathrm{m}$ Millipore filter. The filtered protein solution, which was contained in a test tube (diameter $0.4 \mathrm{~cm}$ ), was placed in a homemade water cell connected to a circulating water bath. The actual temperature of the sample was measured (with a precision of $0.1^{\circ} \mathrm{C}$ ) by placing a thermocouple close to the test tube containing the sample. A $0.4 \mathrm{~mW} \mathrm{He}-\mathrm{Ne}$ laser was focused on the sample, and the transmitted light intensity was received by a photodiode. Transmitted light intensity, temperature of the sample, and time were all recorded.

To induce phase transitions, the samples, which were initially maintained in the stable single-phase state at $37^{\circ} \mathrm{C}$, were quenched to temperatures where phase separation was known to occur. To monitor opacification and phase separation as a function of time for a given fixed temperature, the turbidity, $\tau(t)$, was employed. This quantity was calculated from $\tau(t)=(1 / L) \ln [I(0) / I(t)]$, where $I(0)$ is the initial value of the transmitted intensity, $I(t)$ is the transmitted intensity at time $t$, and $L=0.4 \mathrm{~cm}$ is the internal diameter of the test tube. Two distinct behaviors in the kinetic evolution of opacification were encountered. In one case, $\tau(t)$ steadily increases with time after the quench. In the other case, the value of $\tau(t)$ stays equal to zero after the quench until, after a well-defined induction time is reached, a rapid increase of turbidity is observed. To characterize the rate of opacification, we respectively report the time, $t_{\tau=1}$, at which the turbidity $\tau$ is equal to $1.0 \mathrm{~cm}^{-1}$ for the first case and the induction time, $t_{\text {ind }}$, for the second case.

The values of phase-separation temperatures, $T_{\mathrm{ph}}$, for a given protein concentration, $C$, were obtained by monitoring $\tau(t)$ at several temperatures. We employed two different methods for measuring $T_{\mathrm{ph}}$, depending on the kinetic evolution of opacification. If $\tau(t)$ steadily increases with time, we applied the following method (method I). The sample was initially maintained in the single-phase state, and the initial value of the transmitted light intensity was registered. Due to the generally slow rate of opacification, the temperature of the water bath was then lowered by $1{ }^{\circ} \mathrm{C}$ every $30 \mathrm{~min}$. The temperature, $T_{\text {cloud, }}$ at which the turbidity starts to increase was recorded. The temperature of the water bath was then raised in $0.5^{\circ} \mathrm{C}$ increments and the turbidity was recorded as a function of time. The temperature, $T_{\text {clear }}$, at which the transmitted intensity would recover its initial value in less than 30 min was recorded. The temperature reported for the onset of the phase separation was $T_{\mathrm{ph}}=\left(T_{\text {cloud }}+\right.$ $\left.T_{\text {clear }}\right) / 2$.

If an increase of $\tau(t)$ could be detected only after impractically large induction times, we applied the following method (method II). The sample was initially maintained in the single-phase state, and the initial value of the transmitted light intensity was registered. The temperature of the sample was then lowered significantly so that phase separation occurred with a short induction time. After the short induction 
time, the turbidity started to increase due to phase separation. The temperature of the water bath was then raised in $0.5^{\circ} \mathrm{C}$ increments every $30 \mathrm{~min}$ and the transmitted intensity was recorded as a function of time. The temperature, $T_{\text {clear, }}$ at which the transmitted intensity recovered its initial value in less than 30 min was recorded. The temperature reported for the onset of the phase separation was $T_{\mathrm{ph}}=T_{\text {clear }}$.

A third method was employed for samples with small supersaturations (method III). In this case the condensed state was produced in a region of the phase diagram where the induction time was short (large supersaturation). Then the protein condensed phase was removed and combined with fresh buffer. The samples were then stirred and allowed to equilibrate at a given temperature, $T_{\mathrm{ph}}$, for about $10 \mathrm{~h}$. The protein concentration, $C$, of the supernatant was then determined by UV absorption. This enabled us to obtain the location of points along the low-concentration region of the phase diagram.

Light Microscopy. Aliquots $(2 \mu \mathrm{L})$ of protein solutions were observed on $35 \mathrm{~mm}$ Petri dishes by using an inverted light microscope (Diaphot-TMD, Nikon). Images were taken with a camera (Sony, DXC-970MD) and digitized with a built-in frame-grabber on a Power Macintosh computer.

A temperature-controlled cell (BC-250W) was mounted on the microscope with a heat exchanger, model HEC-400. The temperature was changed with the Bionomic controller BC-100 (20/20 Technology, Wilmington, NC).

\section{RESULTS}

This section is divided into four parts. In the first part we characterize the effect of truncation on individual $\beta \mathrm{B} 1$ and $\beta \mathrm{B} 1 \Delta \mathrm{N} 41$ molecules by measurements of CD spectra and QLS. In the second part, we use QLS to determine the apparent hydrodynamic radius of these same proteins as a function of both total protein concentration and temperature. In the third part, we report the phase boundaries in the temperature-concentration phase diagram for $\beta \mathrm{B} 1 \Delta \mathrm{N} 41$ aqueous solutions. These phase transitions were not observed in the case of $\beta \mathrm{B} 1$ aqueous solutions. In the fourth and final part, we use PEG to actually induce phase separation in $\beta \mathrm{B} 1$ aqueous solutions.

Effect of Truncation on Individual Proteins. The structure of the two proteins, $\beta \mathrm{B} 1$ and $\beta \mathrm{B} 1 \Delta \mathrm{N} 41$, were investigated by circular dichroism (CD). CD measurements in the nearUV range (data not shown), suggest that truncation does not significantly affect the CD spectra. The $\mathrm{N}$-terminal sequence does not significantly contribute to the CD spectra because there are no Trp, Tyr, or Cys residues. Thus the identity of the two CD spectra implies that, apart from the N-terminal arm, the two three-dimensional structures are essentially the same. We also observe that truncation does not affect the thermal stability of the protein, and unfolding was detected at $56{ }^{\circ} \mathrm{C}$ in both cases in agreement with the urea-induced denaturation studies reported by Kim et al. (23).

In Figure 1, we present the far-UV CD spectra for $\beta \mathrm{B} 1$ and the truncated $\beta \mathrm{B} 1 \Delta \mathrm{N} 41$. These $\mathrm{CD}$ spectra are in agreement with the results previously reported by Lampi et al. on $\beta$ B1 (19) and Kim et al. on $\beta \mathrm{B} 1 \Delta \mathrm{N} 41$ (23). Since it is the peptide backbone that absorbs in the far-UV range, truncation of 41 amino acids is expected to affect the value of the molar ellipticity. The difference in molar ellipticity,

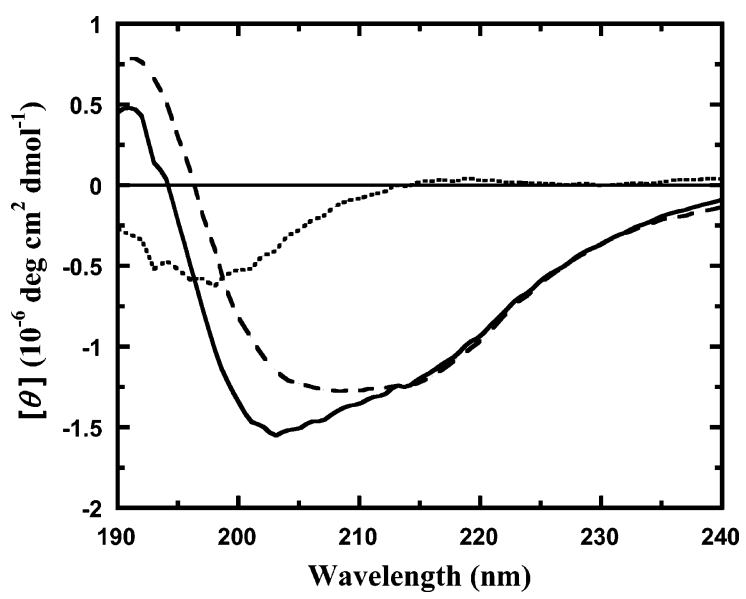

FIGURE 1: Far-UV CD spectra for $\beta \mathrm{B} 1$ (-) and $\beta \mathrm{B} 1 \Delta \mathrm{N} 41$ (---). The dotted line $(\cdots)$ is the difference in molar ellipticity, $[\theta]$, between $\beta \mathrm{B} 1$ and $\beta \mathrm{B} 1 \Delta \mathrm{N} 41$.

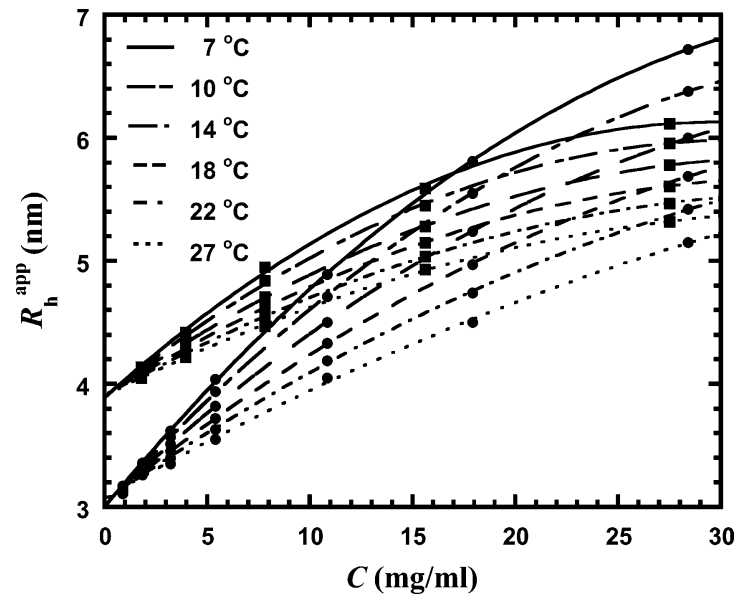

FIGURE 2: Apparent hydrodynamic radius, $R_{\mathrm{h}}$ app, as a function of protein concentration, $C$, for $\beta \mathrm{B} 1(\mathbf{\square})$ and $\beta \mathrm{B} 1 \Delta \mathrm{N} 41(\boldsymbol{)})$ at several temperatures: $7,10,14,18,22$, and $27^{\circ} \mathrm{C}$. At $C=0, R_{\mathrm{h}}$ app is the actual hydrodynamic radius of the protein, $R_{\mathrm{h}}{ }^{\circ}$. The curves for $\beta \mathrm{B} 1$ and $\beta \mathrm{B} 1 \Delta \mathrm{N} 41$ are quadratic fit to the data.

$[\theta]$, between $\beta \mathrm{B} 1$ and $\beta \mathrm{B} 1 \Delta \mathrm{N} 41$, also plotted in Figure 1 , represents the contribution of the $\mathrm{N}$-terminal extension. This difference spectrum displays a minimum at about $197 \mathrm{~nm}$ as in the case of peptides with a random coillike structure (31) and accounts for the observed shift of the $\beta \mathrm{B} 1$ minimum compared to $\beta \mathrm{B} 1 \Delta \mathrm{N} 41$.

The hydrodynamic radii for $\beta \mathrm{B} 1$ and $\beta \mathrm{B} 1 \Delta \mathrm{N} 41$ were determined by quasielastic light scattering (QLS). In Figure 2 , the apparent hydrodynamic radius, $R_{\mathrm{h}}{ }^{\text {app }}$, is reported as a function of protein concentration, $C$, for $\beta \mathrm{B} 1$ and $\beta \mathrm{B} 1 \Delta \mathrm{N} 41$ at six different temperatures. The hydrodynamic radius, $R_{\mathrm{h}}{ }^{\circ}$, of individual $\beta \mathrm{B} 1$ and $\beta \mathrm{B} 1 \Delta \mathrm{N} 41$ was obtained by extrapolating to $C=0, R_{\mathrm{h}}{ }^{\text {app }}(C, T)$ (see Figure 2$)$. This value was found to be temperature-independent within the experimental error. Thus we obtain $R_{\mathrm{h}}{ }^{\mathrm{O}}=3.9 \pm 0.1 \mathrm{~nm}$ for $\beta \mathrm{B} 1$ and $R_{\mathrm{h}}{ }^{\mathrm{o}}$ $=3.0 \pm 0.1 \mathrm{~nm}$ for $\beta \mathrm{B} 1 \Delta \mathrm{N} 41$.

These results can be compared with the hydrodynamic radii obtained for the $\gamma$-crystallins. In the case of $\gamma \mathrm{S}-, \gamma \mathrm{D}$-, and $\gamma \mathrm{B}$-crystallins, it was found that $R_{\mathrm{h}}{ }^{\mathrm{o}}=2.5 \pm 0.1 \mathrm{~nm}$ $(15,16,30)$. Thus the hydrodynamic radius of $\beta \mathrm{B} 1 \Delta \mathrm{N} 41$ is $20 \%$ larger than the value reported for the $\gamma$-crystallins. From $\mathrm{X}$-ray data on protein three-dimensional structures, it can be deduced that the monomeric units of truncated $\beta \mathrm{B} 1 \Delta \mathrm{N} 41$ 
and $\gamma \mathrm{B}$ can be superimposed with very small differences (13). Thus the difference in hydrodynamic radius of $20 \%$ between $\beta \mathrm{B} 1 \Delta \mathrm{N} 41$ and $\gamma \mathrm{B}$ appears to result from the dimeric character of $\beta \mathrm{B} 1 \Delta \mathrm{N} 41$. This expectation is borne out by considering that cross-linked $\gamma \mathrm{D}$ dimers have a hydrodynamic radius $20 \%$ larger than $\gamma$ D monomers (30).

From the $R_{\mathrm{h}}{ }^{0}$ values of $\beta \mathrm{B} 1$ and $\beta \mathrm{B} 1 \Delta \mathrm{N} 41$, we also observe that the presence of the $\mathrm{N}$-terminal arm produces a large $30 \%$ increase of the hydrodynamic radius for $\beta \mathrm{B} 1$ relative to $\beta \mathrm{B} 1 \Delta \mathrm{N} 41$. This is consistent with the presence of N-terminal arms, which significantly increase the effective size of this protein by their extension outside the globular domains of the proteins.

Oligomerization of $\beta B 1$ and $\beta B 1 \triangle N 41$ in Aqueous Solution. Self-association of both $\beta \mathrm{B} 1$ and $\beta \mathrm{B} 1 \Delta \mathrm{N} 41$ in aqueous solution was first investigated by size-exclusion HPLC and QLS. The HPLC measurements were performed at room temperature $\left(21^{\circ} \mathrm{C}\right)$ and agree with previous results $(10,18)$. These measurements show that the retention time for $\beta \mathrm{B} 1$ and $\beta \mathrm{B} 1 \Delta \mathrm{N} 41$ solutions is a function of protein concentration (see Figures 2 and 3 of ref 10). This characteristic, which is not observed in the case of $\gamma$-crystallins, indicates reversible oligomerization for both $\beta \mathrm{B} 1$ and $\beta \mathrm{B} 1 \Delta \mathrm{N} 41$ in solution.

To more quantitatively investigate the effect of truncation on the oligomerization process, we used our measurements of $R_{\mathrm{h}}$ app versus total protein concentration, $C$. These are reported in Figure 2. Our QLS measurements confirm the presence of association. In both cases $(\beta \mathrm{B} 1$ and $\beta \mathrm{B} 1 \Delta \mathrm{N} 41)$, as the protein concentration increases, the value of $R_{\mathrm{h}}{ }^{\text {app }}$ significantly increases with respect to its value $R_{\mathrm{h}}{ }^{0}$ at $C=$ 0 . Furthermore, this figure shows that the extent of oligomerization is significantly dependent on the temperature at fixed concentration. In the case of $\beta \mathrm{B} 1, R_{\mathrm{h}}{ }^{\text {app }} / R_{\mathrm{h}}{ }^{\circ}$ at $C=30$ $\mathrm{mg} / \mathrm{mL}$ was found to be 1.58 at $7^{\circ} \mathrm{C}$ and 1.36 at $27^{\circ} \mathrm{C}$; in the case of $\beta \mathrm{B} 1 \Delta \mathrm{N} 41$, the corresponding values were found to be 2.27 at $7{ }^{\circ} \mathrm{C}$ and 1.70 at $27{ }^{\circ} \mathrm{C}$. On the other hand, $R_{\mathrm{h}}{ }^{\text {app }} / R_{\mathrm{h}}{ }^{\circ}$ for $\gamma$-crystallins was generally found not to exceed 1.2 within the same concentration and temperature domains $(15,16)$. Thus, our QLS measurements not only show the presence of protein-protein association but also reveal that protein cluster size increases upon decreasing the temperature for both proteins. In the case of $\beta \mathrm{B} 1 \Delta \mathrm{N} 41$, average cluster size increases as the temperature approaches one of the phase boundaries to be reported below. Furthermore, association of $\beta \mathrm{B} 1$ is significantly less than association of $\beta \mathrm{B} 1 \Delta \mathrm{N} 41$ at each temperature. This behavior is consistent with the view that the $\mathrm{N}$-terminus, which is extended outside the globular domain of the protein, sterically inhibits oligomer formation.

Phase Behavior of the $\beta B 1$ and $\beta B 1 \triangle N 41$ Aqueous Systems. Liquid-liquid phase separation (LLPS) and crystallization are observed for several $\gamma$-crystallins (24-31). LLPS is described by the phase boundary, $T_{\mathrm{ph}}(C)$, in the phase diagram. This boundary exhibits a maximum at the critical temperature $T_{\mathrm{c}}\left(C_{\mathrm{c}}\right)$ and $C_{\mathrm{c}}$ is the critical concentration. At temperatures lower than its critical value, the $T_{\mathrm{ph}}(C)$ phase boundary describes the equilibrium between two coexisting phases, I and II, with different protein concentrations, $C^{\mathrm{I}}$ and $C^{\mathrm{II}}$, and the same temperature, $T_{\mathrm{ph}}\left(C^{\mathrm{I}}\right)=T_{\mathrm{ph}}\left(C^{\mathrm{II}}\right)$. This phase transition is metastable with respect to crystallization (28).

No phase transition could be detected in the case of $\beta \mathrm{B} 1$ aqueous solutions for protein concentrations as high as 250

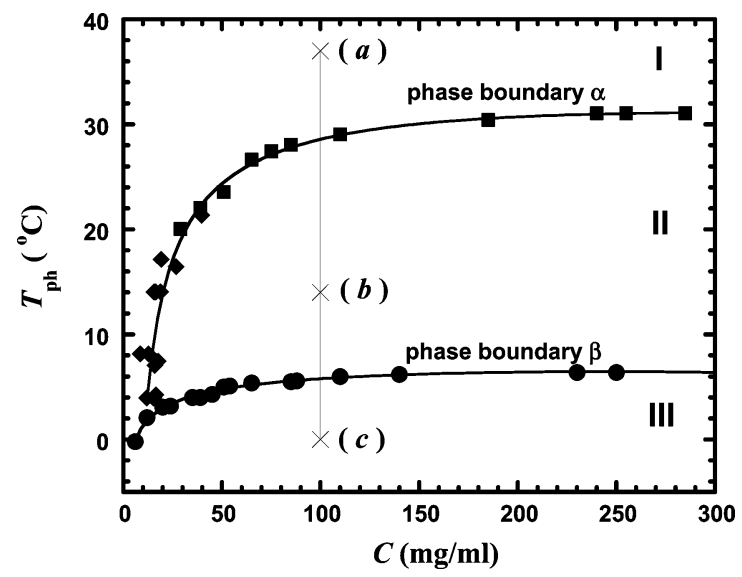

FIGURE 3: Phase diagram of the $\beta \mathrm{B} 1 \Delta \mathrm{N} 41$ aqueous system: Phase boundaries relative to $(\boldsymbol{\square}, \boldsymbol{)})$ the formation of rodlike assemblies (phase boundary $\alpha$ ) and $(\boldsymbol{)})$ heterogeneous gelation (phase boundary $\beta$ ). The solid curves passing through the data are eye-guides. The phase diagram is made of the following domains: homogeneous solutions (I), rodlike assemblies (II), and heterogeneous gelation (III). States $a-c$ show a representative path for obtaining the experimental results. The data points were obtained by methods I $(\bullet)$, II (ם), and III $(\diamond)$ as described under Materials and Methods.

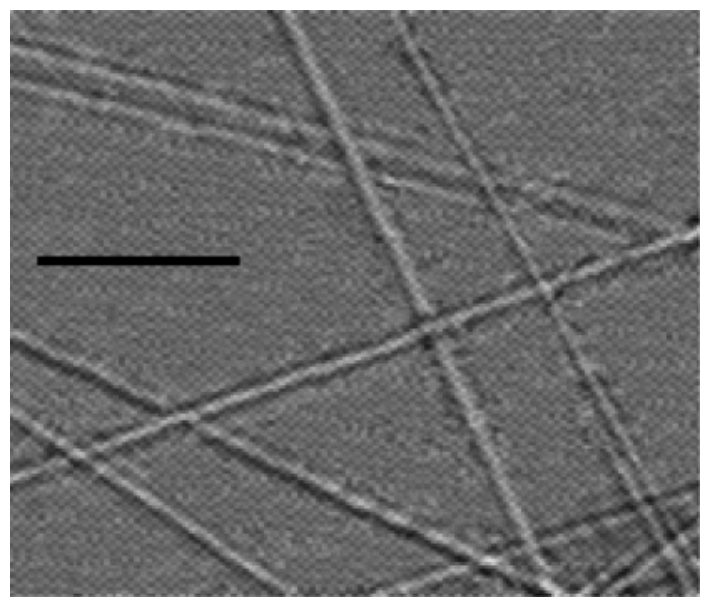

FIGURE 4: Images taken with a phase-contrast light microscope: Formation of rodlike assemblies during phase separation at $T=$ $20{ }^{\circ} \mathrm{C}$ of a $\beta \mathrm{B} 1 \Delta \mathrm{N} 41$ aqueous solution with $C=50 \mathrm{mg} / \mathrm{mL}$. The length of the horizontal bar is $10 \mu \mathrm{m}$.

$\mathrm{mg} / \mathrm{mL}$ and temperatures as low as $-10{ }^{\circ} \mathrm{C}$. On the other hand, two distinct phase transformations were observed in the case of truncated $\beta \mathrm{B} 1 \Delta \mathrm{N} 41$ aqueous solutions. In Figure 3 , we report the temperature-concentration phase diagram for the $\beta \mathrm{B} 1 \Delta \mathrm{N} 41$ aqueous system. The two phase boundaries, $\alpha$ and $\beta$, separate the phase diagram into three domains: I, II, and III. To describe the phase transition properties of the $\beta \mathrm{B} 1 \Delta \mathrm{N} 41$ aqueous system in Figure 3, we consider a protein solution that is initially in a state of domain I, where no phase transformation occurs. Upon quenching of the protein solution to a state of domain II, a dramatic increase of sample turbidity is observed after a well-defined induction time. If the opaque sample is brought back into domain I within a few hours, it becomes transparent again, demonstrating reversibility.

This I-II phase transformation is related to the formation of large protein scattering elements. To characterize the morphology of these elements, we have used light microscopy. Figure 4 reveals that these protein assemblies display a regular rodlike shape. We will refer to them as "rodlike 


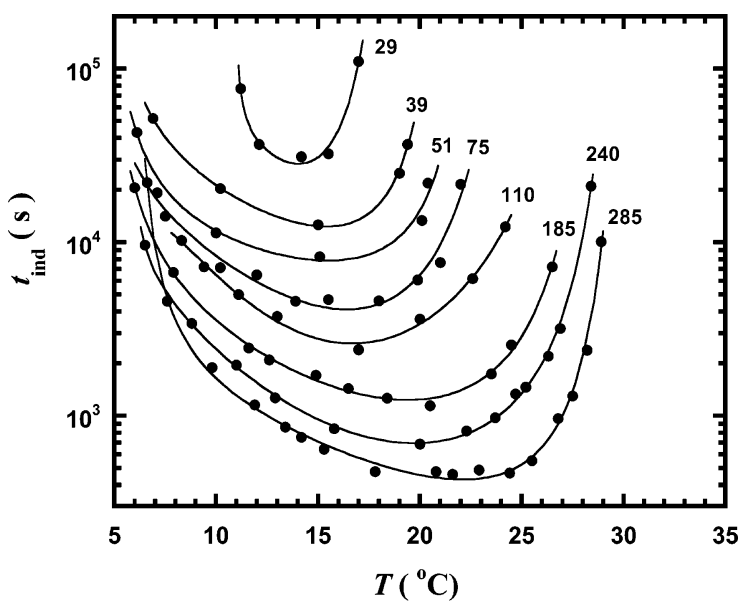

FIGURE 5: Induction time, $t_{\text {ind }}$, for the formation of rodlike assemblies as a function of temperature, $T$, and for several protein concentrations of $\beta \mathrm{B} 1 \Delta \mathrm{N} 41$ aqueous solutions. The solid curves are guides for the eye. The numbers associated with each curve identify the corresponding values of $C$ (in milligrams per milliliter).

assemblies". The rod thickness is $\approx 1 \mu \mathrm{m}$ and is virtually identical for all the assemblies; the rod length is generally larger than $100 \mu \mathrm{m}$ and varies significantly from rod to rod. Phase boundary $\alpha$ in Figure 3 thus describes protein solubility with respect to the rodlike assemblies.

We have investigated the kinetics for the formation of the rodlike assemblies. Protein samples of a given protein concentration $C$ were quenched from $\approx 37^{\circ} \mathrm{C}$ to a temperature $T$ inside domain II and the sample turbidity was monitored as a function of time. It was found that the rodlike assemblies appear only after an induction time $\left(t_{\text {ind }}\right)$ has elapsed. No intermediate mesoscopic protein cluster could be detected by QLS prior to the induction time. After the induction time has been reached, the presence of large heterogeneities inside the samples precludes the use of QLS. In Figure 5, we report the induction time, $t_{\text {ind }}$, as a function of temperature, $T$, for several protein concentrations, $C$. At fixed temperature, we generally find that $t_{\text {ind }}$ increases as the protein concentration decreases. At fixed protein concentration, we find that, starting from phase boundary $\alpha$ of Figure 3 and decreasing the temperature along a path at constant protein concentration, $t_{\text {ind }}$ first decreases and then increases, becoming large near phase boundary $\beta$. In Figure 5 , we can also see that the temperature at which the minimum occurs increases with protein concentration. Furthermore, near phase boundary $\beta$, the induction time values of various concentrations at $C \gtrsim 50 \mathrm{mg} / \mathrm{mL}$ tend to come close to one another. The significance of these $t_{\text {ind }}$ data will be discussed in the next section.

The rodlike assemblies shown in Figure 4 are actually found to be intermediate structures leading to the formation of more thermodynamically stable protein crystals shown in Figure 6. Indeed, if an opaque sample is left inside domain II for a long time (from 1 day to 1 week) and then the temperature is increased up to $37{ }^{\circ} \mathrm{C}$ (into domain I), this sample may now remain opaque in this state. By light microscopy, we observed that the thickness of the rodlike assemblies had increased up to $\approx 5 \mu \mathrm{m}$ and birefringence is clearly observed as it would be expected for crystalline structures. These thicker assemblies were equilibrated with fresh buffer solutions and the protein solubility relative to these crystals was determined as a function of temperature

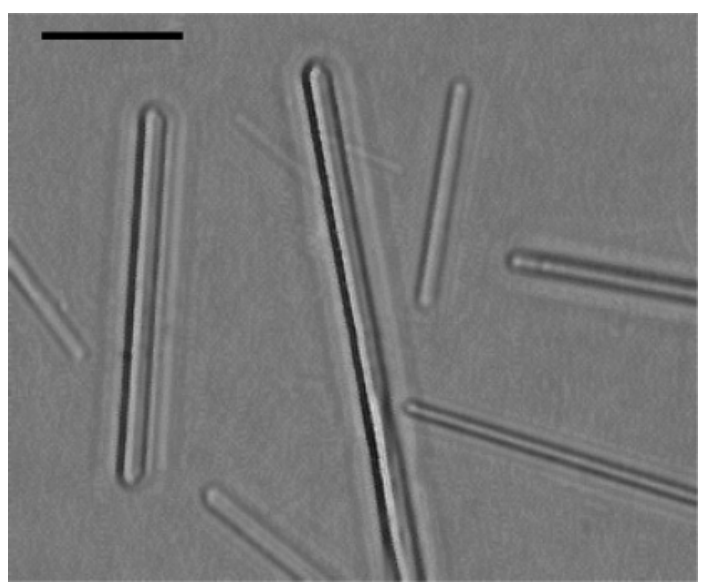

FIGURE 6: Images taken with a phase-contrast light microscope: Formation of $\beta \mathrm{B} 1 \Delta \mathrm{N} 41$ crystals. The length of the horizontal bar is $20 \mu \mathrm{m}$.

(by method III as described under Materials and Methods). We find approximately that the protein solubility linearly increases from 8 to $19 \mathrm{mg} / \mathrm{mL}$ when the temperature is increased from 3 to $37^{\circ} \mathrm{C}$, demonstrating that phase boundary $\alpha$ has shifted toward lower protein concentrations. These new solubility values describe the more stable thermodynamic phase boundary. It is important to remark that these crystalline structures can only be generated inside domain II of Figure 3.

We now consider domain III of the phase diagram. Upon quenching of the protein solution from domain I rapidly to domain III, a second distinct phase transition was observed, accompanied by the formation of an opaque gellike material rich in protein. We find that, at protein concentrations lower than $\approx 100 \mathrm{mg} / \mathrm{mL}$, a (transparent) liquid phase could be separated from a gellike opaque fraction by centrifugation. The concentration of protein inside the gellike fraction was found to be $\approx 100 \mathrm{mg} / \mathrm{mL}$. The measured protein concentrations of the supernatant for $C<100 \mathrm{mg} / \mathrm{mL}$ are consistent with the concentration data defining phase boundary $\beta$ in Figure 3, which were determined by turbidity (method I as dexcribed under Materials and Methods). At protein concentrations larger than $\approx 100 \mathrm{mg} / \mathrm{mL}$, no macroscopic phase separation of the opaque samples was observed even after centrifugation at $4300 \mathrm{~g}$ for $6 \mathrm{~h}$. These samples do not flow if the test tubes are tilted. This implies gellike properties extending throughout the sample. The opacity of the samples is clear evidence of protein concentration heterogeneities on the length scale of the wavelength of light. We will refer to the observed phase transformation as "heterogeneous gelation". This heterogeneous gelation is thermoreversible. If the opaque sample is brought from domain III back to domain I, it becomes transparent again. Furthermore, if the opaque sample is brought from domain III to domain II, it first becomes transparent and then, after a given time, rodlike assemblies are observed. Interestingly, if a sample containing rodlike assemblies is quenched from domain II to domain III, no phase transformation occurs. This is consistent with heterogeneous gelation being metastable with respect to rodlike assemblies. An analogous situation occurs in the case of $\gamma$-crystallin solutions, where liquid-liquid phase separation (LLPS) is found to be metastable with respect to protein crystals (24-28). 


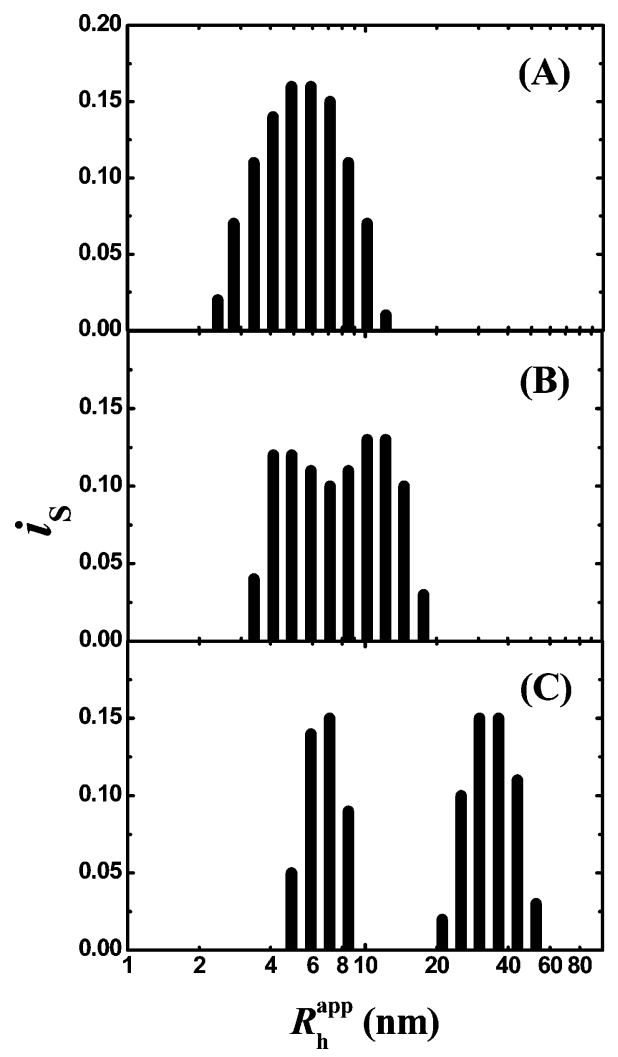

FIGURE 7: Normalized scattered intensity, $i_{\mathrm{S}}$, as a function of the apparent hydrodynamic radius, $R_{\mathrm{h}}$ app, for $\beta \mathrm{B} 1 \Delta \mathrm{N} 41$ solutions at $C$ $=12 \mathrm{mg} / \mathrm{mL}$ and for three representative times: $1 \mathrm{~min}(\mathrm{~A}), 15$ $\min (\mathrm{B})$, and $150 \min (\mathrm{C})$ after the quench at $2.0^{\circ} \mathrm{C}$.

To further investigate heterogeneous gelation, we performed QLS and light microscope measurements on condensation at low $\beta \mathrm{B} 1 \Delta \mathrm{N} 41$ concentrations $(10-20 \mathrm{mg} / \mathrm{mL})$ and near phase boundary $\beta$. Contrary to the rodlike assembly case, intermediate mesoscopic protein clusters can be detected. We have used QLS to determine the molecular size distribution as a function of time. We have quenched $\beta \mathrm{B} 1 \Delta \mathrm{N} 41$ solutions at $37{ }^{\circ} \mathrm{C}$ (inside domain I) to $2.0{ }^{\circ} \mathrm{C}$ (inside domain III). QLS measurements were performed at temperatures only slightly lower than the temperature of phase boundary $\beta$. Here the rate of phase transformation was low and the size distribution as a function of time could be accurately monitored. In Figure 7 , we report the $\beta \mathrm{B} 1 \Delta \mathrm{N} 41$ size distribution at $C=12 \mathrm{mg} / \mathrm{mL}$ and for three representative times after the quench to $2.0^{\circ} \mathrm{C}$. One minute after the quench (panel A), the distribution is monomodal with an average $R_{\mathrm{h}}$ app of about $6 \mathrm{~nm}$. This value of hydrodynamic radius at $2.0^{\circ} \mathrm{C}$ and $C=12 \mathrm{mg} / \mathrm{mL}$ is consistent with the data reported in Figure 2 and represents the protein oligomers (made of 4-6 protein dimers). After 15 min (panel B), the distribution broadens, showing the formation of higher molecular weight protein clusters. After $150 \mathrm{~min}$ (panel C), the distribution is clearly bimodal. We can see that the first peak remains at $R_{\mathrm{h}}$ app $\approx 6 \mathrm{~nm}$ and corresponds to the low molecular weight oligomers; the second peak corresponds to mesoscopic scattering elements. Their size increases with time and ultimately becomes on the order of the wavelength of light. About $5 \mathrm{~h}$ after quenching of the sample to $2.0^{\circ} \mathrm{C}$, macroscopic assemblies could be distinctly observed by light microscopy. These assemblies appear to possess a globular shape as in the case of droplets found in LLPS. The particle

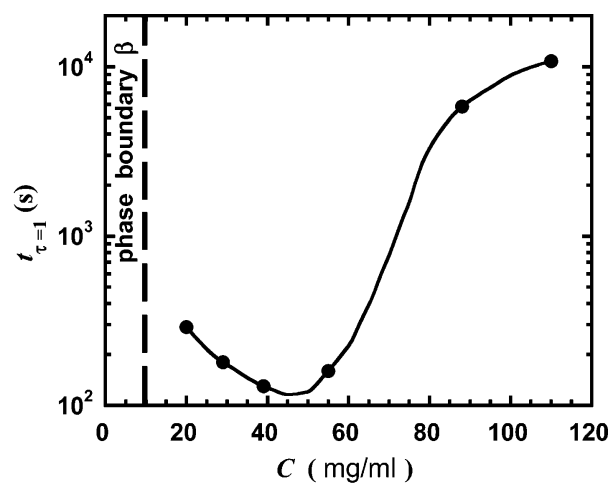

FIgURE 8: Time, $t_{\tau=1}$, at which $\tau=1.0 \mathrm{~cm}^{-1}$, as a function of $\beta \mathrm{B} 1 \Delta \mathrm{N} 41$ concentration, $C$, at the representative temperature, $T$ $=1.0^{\circ} \mathrm{C}$. The solid curve is a guide for the eye. The vertical dashed line locates phase boundary $\beta$ at $1.0{ }^{\circ} \mathrm{C}$.

diameter is $\approx 1 \mu \mathrm{m}$. These globular assemblies are observed to undergo Brownian motion as it was observed by Broide et al. (25) in the case of $\gamma$-crystallin, protein-rich liquid droplets surrounded by a protein-poor liquid domain. However, in contrast to the $\gamma$-crystallin case, neither coarsening nor coalescence of the globular assemblies was observed under microscope. Our experimental observations are consistent with the view that domain III represents LLPS accompanied by gelation within the protein-rich phase. Indeed, $\beta \mathrm{B} 1 \Delta \mathrm{N} 41$ forms reversible oligomers in solution in contrast to $\gamma$-crystallins. It is likely that this phenomenon of reversible association, which will produce large protein clusters at high concentrations, is the basis of the gelation within the protein-rich phase. This gelation prevents coarsening and coalescence of the droplets.

We also investigated the kinetics of heterogeneous gelation as $\beta \mathrm{B} 1 \Delta \mathrm{N} 41$ concentration increases. Samples with increasing protein concentration were quenched to a temperature $T$ into domain III and the turbidity was monitored as a function of time. Contrary to the rodlike assembly case, turbidity for heterogeneous gelation was found to increase immediately after the quench. A convenient way to describe the rate of opacification is to consider the time, $t_{\tau=1}$, at which $\tau(t)$ is equal to $1.0 \mathrm{~cm}^{-1}$. In Figure 8, we report $t_{\tau=1}$ as a function of protein concentration at the representative temperature, $T$ $=1.0{ }^{\circ} \mathrm{C}$. We can see that $t_{\tau=1}$ decreases (the rate of opacification increases) as $C$ moves away from phase boundary $\beta$ as expected. However, for $C$ larger than $\approx 50$ $\mathrm{mg} / \mathrm{mL}, t_{\tau=1}$ starts to dramatically increase with protein concentration. At $C \approx 100 \mathrm{mg} / \mathrm{mL}, t_{\tau=1}$ is 2 orders of magnitude larger than at $C \approx 50 \mathrm{mg} / \mathrm{mL}$. At this concentration, macroscopic phase separation is also not observed. Indeed, at this concentration, the domain where the gel forms is so large that it creates a network spanning the whole system. Hence, for the components to partition toward the thermodynamic equilibrium concentrations, they have to diffuse through a very viscous medium because of the concomitant formation of the gel network. This gel network reduces the dynamics of phase separation and ultimately "freezes" the entire protein sample. This is again consistent with the presence of LLPS accompanied by gelation within the protein-rich liquid phase. Indeed, this result can be directly associated with the formation of the bicontinuous structure (i.e., two interlaced networks) of two interconnected liquid domains observed in the case of $\gamma$-crystallin LLPS at 


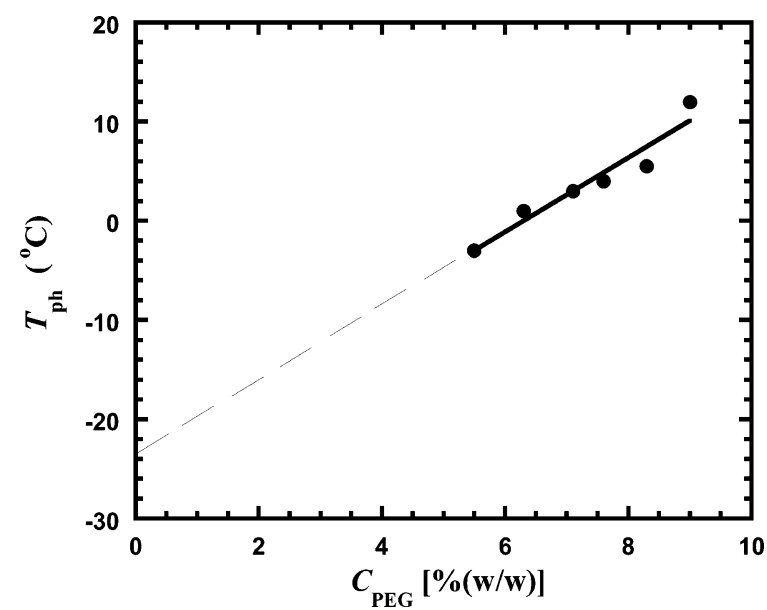

FIGURE 9: Temperature of phase separation, $T_{\mathrm{ph}}$, as a function of PEG1450 concentration, $C_{\mathrm{PEG}}$, at constant protein concentration $(C$ $=100 \mathrm{mg} / \mathrm{mL}$ ) for $\beta \mathrm{B} 1-\mathrm{PEG}$ solutions. The data were fitted to a straight line (solid line). The dashed line represents a linear extrapolation of the data to $C_{\mathrm{PEG}}=0$.

concentrations approaching the critical concentration (25). However the protein-rich and the protein-poor $\gamma$-crystallin domains will always form two macroscopic liquid phases separated by a meniscus under the influence of a gravitational field or by centrifugation since gelation does not occur.

Phase Separation of $\beta B 1$ Solutions in the Presence of $P E G$. We have previously shown that, in the case of $\gamma \mathrm{S}$ crystallin aqueous solutions, the addition of PEG can raise the temperature of phase separation into the accessible temperature domain, that is, above the freezing point (30, 33). By this means, it was possible to estimate by extrapolation, the temperature of phase separation for the $\gamma \mathrm{S}$-crystallin aqueous system, which lies below the freezing point. Therefore, to observe phase separation in $\beta \mathrm{B} 1$ aqueous solutions and compare its phase behavior with that of $\beta \mathrm{B} 1 \Delta \mathrm{N} 41$, we have added PEG1450 to native $\beta \mathrm{B} 1$ aqueous solutions. We succeeded in observing phase separation for the $\beta \mathrm{B} 1+\mathrm{PEG}$ aqueous mixture analogous to that found for $\beta \mathrm{B} 1 \Delta \mathrm{N} 41$ inside domain III. We measured the temperature of phase separation, $T_{\mathrm{ph}}$, as a function of PEG concentration, $C_{\mathrm{PEG}}$, at constant protein concentration $(C=$ $100 \mathrm{mg} / \mathrm{mL}$ ). The data are reported in Figure 9.

The figure shows that $T_{\mathrm{ph}}$ increases with $C_{\mathrm{PEG}}$. A satisfactory estimate of $T_{\mathrm{ph}}$ for the PEG-free system at this protein concentration can be obtained by extrapolating the $T_{\mathrm{ph}}$ values (at $C=100 \mathrm{mg} / \mathrm{mL}$ ) to $C_{\mathrm{PEG}}=0$. We find that $T_{\mathrm{ph}}$ falls between -20 and $-30{ }^{\circ} \mathrm{C}$. We therefore conclude that $T_{\mathrm{ph}}$ of the $\beta \mathrm{B} 1$ aqueous system is about $30{ }^{\circ} \mathrm{C}$ lower than the corresponding $T_{\mathrm{ph}}$ for the case of $\beta \mathrm{B} 1 \Delta \mathrm{N} 41$ aqueous system (phase boundary $\beta$ in Figure 3 ). Since the difference in critical temperature, $T_{\mathrm{c}}$, is also expected to be about $30^{\circ} \mathrm{C},{ }^{2}$ we conclude that the presence of the $\mathrm{N}$-terminal arm produces a $10 \%$ decrease in $T_{\mathrm{c}}$ (from 279.6 to $\approx 250 \mathrm{~K}$ ). In

\footnotetext{
${ }^{2}$ The dependence of $T_{\mathrm{ph}}$ on $C$ vanishes at its maximum, that is, the critical temperature, $T_{\mathrm{c}}$. In the case of $\beta \mathrm{B} 1 \Delta \mathrm{N} 41$, the small change of $T_{\mathrm{ph}}(C)$ observed at higher protein concentrations indicates that $T_{\mathrm{ph}}$ is approaching $T_{\mathrm{c}}$ equal to $279.6 \mathrm{~K}\left(6.4{ }^{\circ} \mathrm{C}\right.$ in Figure 3$)$. In the case of $\beta \mathrm{B} 1$, Figure 9 shows that $T_{\mathrm{ph}} \approx 250 \mathrm{~K}$ at $C=80 \mathrm{mg} / \mathrm{mL}$. Since $T_{\mathrm{ph}}(C)$ does not significantly change from $C=80$ to $280 \mathrm{mg} / \mathrm{mL}$ in the case of $\beta \mathrm{B} 1 \Delta \mathrm{N} 41$ (see Figure 3), we expect a corresponding weak dependence of $T_{\mathrm{ph}}$ on $C$ in the case of $\beta \mathrm{B} 1$. Hence the value of $T_{\mathrm{c}}$ for $\beta \mathrm{B} 1$ will also be $\approx 250 \mathrm{~K}$.
}

the next section, this difference in $T_{\mathrm{c}}$ will be associated with the corresponding difference in oligomerization energy.

\section{DISCUSSION}

We have found that both $\beta \mathrm{B} 1$ and $\beta \mathrm{B} 1 \Delta \mathrm{N} 41$ undergo reversible oligomerization in aqueous solutions; the degree of oligomerization (i.e., the average cluster size) is greater for the truncated protein than for the native one. We have also found that $\beta \mathrm{B} 1 \Delta \mathrm{N} 41$ aqueous solutions undergo two distinct types of phase transitions. The first phase transition involves an initial formation of thin rodlike assemblies, which then evolve to form crystals. Interestingly, the induction time for the formation of rodlike assemblies displays a minimum as a function of temperature along a path at constant concentration. The second phase transition can be described as LLPS accompanied by gelation within the protein-rich phase. We have referred to this process as heterogeneous gelation. These two phase transitions are not observed in the case of $\beta \mathrm{B} 1$ aqueous solutions. Nevertheless, upon the addition of PEG, heterogeneous gelation was also observed for $\beta \mathrm{B} 1$.

The first goal of this section is to determine the association energy for oligomerization of both $\beta \mathrm{B} 1$ and $\beta \mathrm{B} 1 \Delta \mathrm{N} 41$. To achieve this goal, we will analyze the $R_{\mathrm{h}}{ }^{\text {app }} / R_{\mathrm{h}}{ }^{\mathrm{o}}$ values associated with oligomerization of $\beta \mathrm{B} 1$ and $\beta \mathrm{B} 1 \Delta \mathrm{N} 41$ as reported in Figure 2. The difference in oligomerization energy will be related to the difference in $T_{\mathrm{c}}$ for $\beta \mathrm{B} 1 \Delta \mathrm{N} 41$ as compared to $\beta \mathrm{B} 1$. The second goal of this section is to explain the behavior of the induction time for the formation of $\beta \mathrm{B} 1 \Delta \mathrm{N} 41$ rodlike assemblies as reported in Figure 5. We shall see that the experimental dependence of $t_{\text {ind }}$ on temperature and concentration can be related to both oligomerization and LLPS.

Oligomerization of $\beta B 1$ and $\beta B 1 \triangle N 41$. Protein dimers reversibly associate to form higher order oligomers in solution. In the limit of low protein concentration, $C$, we consider only the dimer-dimer association to form tetramers and neglect higher order associations. In this case, we find (see Appendix for more details) (32):

$$
\frac{R_{\mathrm{h}}{ }^{\mathrm{app}}}{{R_{\mathrm{h}}{ }^{\mathrm{o}}}^{\mathrm{a}}}=1+4(1-s) K_{2} c
$$

where $s$ is the ratio of the dimer hydrodynamic radius to the tetramer hydrodynamic radius, $K_{2}=c_{2} / c_{1}^{2}$ is the association equilibrium constant, $c_{1}$ and $c_{2}$ are respectively the molar concentrations of dimers and tetramers, and $c$ is the total molar concentration. In Figure 2, the mass concentration, $C$, is plotted. This is related to $c$ by $c=C / M_{\mathrm{w}}$, where $M_{\mathrm{w}}$ is the molecular weight of the protein dimer. If we approximate both $\beta \mathrm{B} 1$ and $\beta \mathrm{B} 1 \Delta \mathrm{N} 41$ dimers as spherical particles, we find $s=0.72(35)$. We used eq 1 with $s=0.72$ to fit our values of $R_{\mathrm{h}}{ }^{\text {app }} / R_{\mathrm{h}}{ }^{\circ}$ within the linear concentration range and obtained $K_{2}(T)$ for both $\beta \mathrm{B} 1$ and $\beta \mathrm{B} 1 \Delta \mathrm{N} 41$. In Figure 10, we report the values of $\ln \left(K_{2} c^{0}\right)$, where $c^{0}=1 \mathrm{M}$, as a function of $1 / T$ for both $\beta \mathrm{B} 1$ and $\beta \mathrm{B} 1 \Delta \mathrm{N} 41$ and fit the data to straight lines. We can see that, for each temperature, the value of $K_{2}$ for $\beta \mathrm{B} 1 \Delta \mathrm{N} 41$ is larger than for $\beta \mathrm{B} 1$ as expected from the greater oligomerization of $\beta \mathrm{B} 1 \Delta \mathrm{N} 41$.

It is important to observe that the chosen value for $s$ affects the value of the intercept but not the slope of our linear fits. 


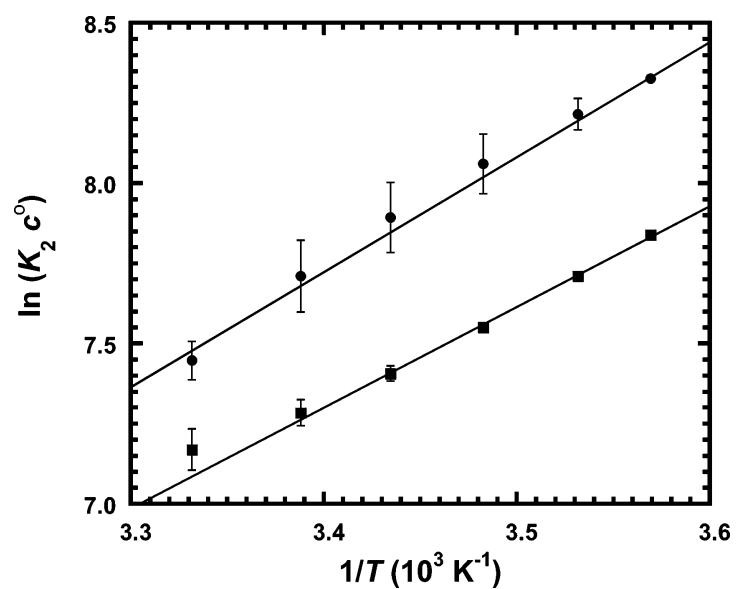

FIGURE 10: Logarithm of the association equilibrium constant, ln $\left(K_{2} c^{\circ}\right)$, as a function of $1 / T$ for both $\beta \mathrm{B} 1(\mathbf{\square})$ and $\beta \mathrm{B} 1 \Delta \mathrm{N} 41(\mathbf{)})$ solutions. The straight lines are linear fits to the data weighted by the standard deviations associated with each point. In the case of $\beta \mathrm{B} 1$, the $\ln \left(K_{2} c^{\circ}\right)$ values and their standard deviations were obtained from linear fits to the $R_{\mathrm{h}}{ }^{\text {app }}$ data with $C<8 \mathrm{mg} / \mathrm{mL}$. In the case of $\beta \mathrm{B} 1 \Delta \mathrm{N} 41$, the $\ln \left(K_{2} c^{\circ}\right)$ values and their standard deviations were obtained from linear fits to the $R_{\mathrm{h}}$ app data with $C<6 \mathrm{mg} / \mathrm{mL}$.

Thus we can use the two slopes in Figure 10 to determine more reliably the standard association enthalpy, $\Delta H_{2}^{\circ}$, by

$$
\frac{\mathrm{d} \ln \left(K_{2} c^{\mathrm{o}}\right)}{\mathrm{d}(1 / T)}=-\Delta H_{2}^{\mathrm{o}} / R
$$

where $R$ is the ideal gas constant. The association enthalpy, $\Delta H_{2}^{\circ}$, for $\beta \mathrm{B} 1$ and $\beta \mathrm{B} 1 \Delta \mathrm{N} 41$ is respectively $-26 \pm 1$ and $-30 \pm 1 \mathrm{~kJ} / \mathrm{mol}$. Therefore, the magnitude of the association enthalpy for $\beta \mathrm{B} 1 \Delta \mathrm{N} 41$ is $\approx 10 \%$ larger that for $\beta \mathrm{B} 1$. Furthermore, from the two values of $\Delta H_{2}^{\circ}$, we see that the association enthalpy for both $\beta \mathrm{B} 1$ and $\beta \mathrm{B} 1 \Delta \mathrm{N} 41$ is $\approx 10 R T$ within the experimental temperature domain $(280 \mathrm{~K}<T<$ $310 \mathrm{~K})$. Interestingly, in the case of $\gamma$-crystallins, the protein - protein attraction energy $(\approx 1.3 R T)$ was found to be 1 order of magnitude smaller within the same temperature range (26). Clearly, this large difference in attraction energy between $\beta \mathrm{B} 1$ and $\gamma$-crystallins is consistent with the presence of reversible oligomerization in the case of $\beta \mathrm{B} 1$ and $\beta \mathrm{B} 1 \Delta \mathrm{N} 41$ solutions.

In the previous section, we have estimated that $T_{\mathrm{c}}$ increases $\approx 10 \%$ from $\beta \mathrm{B} 1$ to $\beta \mathrm{B} 1 \Delta \mathrm{N} 41$. Thus, the increase in $T_{\mathrm{c}}$ produced by truncation at the $\mathrm{N}$-terminus is roughly equal to the corresponding increase in magnitude of the association enthalpy $\Delta H_{2}^{\circ}$. We observe that a change in association entropy due to truncation would also affect the difference in $T_{\mathrm{c}}$ between $\beta \mathrm{B} 1$ and $\beta \mathrm{B} 1 \Delta \mathrm{N} 41$ (36). However, the consistency between the change in $T_{\mathrm{c}}$ and $\Delta H_{2}^{\circ}$ suggests that association entropy changes are less important. This indicates that the increase in oligomerization energy from $\beta \mathrm{B} 1$ to $\beta \mathrm{B} 1 \Delta \mathrm{N} 41$ is responsible for the observed shift of the LLPS phase boundary toward higher temperatures. A shift of $T_{\mathrm{c}}$ toward higher temperature was also obtained when the LLPS phase boundary for $\gamma \mathrm{D}$-crystallin monomers and the corresponding cross-linked oligomers were compared, showing that $T_{\mathrm{c}}$ increases with the size of the oligomer (30). ${ }^{3}$

Induction Time for the Formation of $\beta B 1 \Delta N 41$ Rodlike Assemblies. In the case of the $\beta \mathrm{B} 1 \Delta \mathrm{N} 41$ aqueous system, we have experimentally observed that protein crystallization occurs via the formation of intermediate thin rodlike assemblies. We have measured the induction time, $t_{\text {ind }}$, for the formation of rodlike assemblies as a function of both temperature and concentration. In the previous section, we noted two important features related to the $t_{\text {ind }}$ values reported: (1) $t_{\text {ind }}$ displays a minimum if plotted versus temperature at constant concentration, and (2) the $t_{\text {ind }}$ values for various concentration values at $C \gtrsim 50 \mathrm{mg} / \mathrm{mL}$ tend to come close to one another near the temperature corresponding to phase boundary $\beta$. We now provide a rationale for these two features by relating the induction time to the protein chemical potential, $\mu_{1}$. This quantity, in turn, strongly depends on $\beta \mathrm{B} 1 \Delta \mathrm{N} 41$ self-association or oligomerization in solution.

The induction time is a complex function of thermodynamic and kinetic parameters, and it is very sensitive to both the nucleation mechanism and the employed experimental technique (37). However, since we are only interested in interpreting the qualitative behavior of $t_{\text {ind }}$, we shall use an approximate relationship that allows us to relate the behavior of $\mu_{1}$ to the behavior of $t_{\text {ind }}$ in a simple fashion. This equation, which assumes that $t_{\text {ind }}$ is inversely proportional to the rate of homogeneous nucleation (38), is

$$
t_{\text {ind }}=A \exp (W / R T)
$$

where

$$
\begin{gathered}
\frac{W}{R T}=\frac{g \Omega^{2} \gamma^{3}}{R T\left(\Delta \mu_{1}\right)^{2}} \\
\Delta \mu_{1} \equiv \mu_{1}(T, c)-\mu_{1}\left[T, c^{\mathrm{eq}}(T)\right]
\end{gathered}
$$

In eq $3 \mathrm{a}, A$ is a preexponential kinetic parameter and $W$ is the nucleation work. From classical nucleation theory (37), $W$ is given by eq $3 b$, where $g$ is a geometric coefficient related to the shape of the nucleus $(g=16 \pi / 3$ for a spherical nucleus), $\Omega$ is the volume occupied by a protein in the nucleus, $\gamma$ is the surface tension of the nucleus, and $\Delta \mu_{1}$ is the thermodynamic supersaturation. This quantity is defined by eq $3 \mathrm{c}$, where $\mu_{1}(T, c)$ is the protein chemical potential in solution and $c^{\mathrm{eq}}(T)$ is the protein molar concentration in equilibrium with rodlike assemblies. Indeed, $c^{\mathrm{eq}}(T)$ is the phase boundary $\alpha$ in Figure 3 (there instead of $c$ we use the mass concentration $C$ ).

The use of eq $3 a-c$ has the advantage of expressing clearly the essential dependence of $t_{\text {ind }}$ on the thermodynamic supersaturation, $\Delta \mu_{1}$. Due to the relatively small experimental temperature range ( $279 \mathrm{~K}<T<302 \mathrm{~K}$ ), we do not expect changes of $A, \Omega$, and $T$ to significantly affect the dependence of $t_{\text {ind }}$ on $T$. Both $\gamma$ and $\Delta \mu_{1}$ are expected to depend on temperature. However, the oligomerization phenomenon explicitly affects only the chemical potential of the protein in the liquid phase (see Appendix). The surface tension of the nucleus/solution interface is not directly related to oligomerization in solution. Since the degree of oligomer-

\footnotetext{
${ }^{3}$ However, there is no correlation between the large attraction energy found for $\beta \mathrm{B} 1 \Delta \mathrm{N} 41$ compared to the monomeric $\gamma \mathrm{D}$-crystallin and the nearly equal values of $T_{\mathrm{c}}: 279.6 \mathrm{~K}$ for $\beta \mathrm{B} 1 \Delta \mathrm{N} 41$ and $278.6 \mathrm{~K}$ for $\gamma \mathrm{D}$-crystallin (see ref 30). This apparent inconsistency can be justified by considering the role of anisotropic interactions (e.g., reversible association) on LLPS (see refs 29 and 36).
} 
ization depends significantly on temperature, we expect that the related dependence of $\Delta \mu_{1}$ on $T$ is also large. We will now show that the essential features of the observed dependence of $t_{\text {ind }}$ on temperature and concentration can be accounted for by just examining the behavior of $\Delta \mu_{1}$, assuming $\gamma$ to be constant.

On approaching phase boundary $\alpha$ (in Figure 3), $c \rightarrow c^{\mathrm{eq}}$ and $\Delta \mu_{1} \rightarrow 0$; thus $t_{\text {ind }}$ diverges (see eq $3 \mathrm{a}-\mathrm{c}$ ). This is consistent with the experimentally observed dependence of $t_{\text {ind }}$ on both $T$ and $C$ presented in Figure 5 in the vicinity of the phase boundary $\alpha$. We now consider the dependence of $\Delta \mu_{1}$ on temperature along a path at constant $c$, moving inside domain II. An approximation usually employed for $\Delta \mu_{1}(T$, c) to explain nucleation kinetics is to consider $\mu_{1} \sim \ln c$ and, consequently, $\Delta \mu_{1}=R T \ln \left(c / c^{\mathrm{eq}}\right)$ (37-39). No maximum can be found within the experimental temperature domain if we use this approximation. This happens because, upon lowering the temperature below the phase boundary $\alpha$ at constant $c$ inside domain II of Figure 3, the difference between $c$ and $c^{\mathrm{eq}}(T)$ increases monotonically. Clearly, the presence of the minimum is associated with a decrease of $\Delta \mu_{1}$ at low temperatures that cannot be described by the previous approximation. Indeed, due to chemical equilibrium among the oligomers, a better approximation for $\Delta \mu_{1}$ can be found by considering $\mu_{1} \sim \ln c_{1}$ and $\Delta \mu_{1}=R T \ln \left(c_{1} /\right.$ $c_{1}{ }^{\mathrm{eq}}$ ), where $c_{1}(T, c)$ is the molar concentration of free protein dimers and $c_{1}{ }^{\mathrm{eq}} \equiv c_{1}\left[T, c^{\mathrm{eq}}(T)\right](40-42)$. This approximation implies that only the free protein dimers give rise to crystals, and oligomerization in solution reduces the thermodynamic driving force for crystallization.

As $c$ increases at constant $T, c_{1} / c$ decreases due to oligomerization. Hence, the increase of $\mu_{1} \sim \ln c_{1}$ with $c$ is smaller than that predicted by simply assuming $\mu_{1} \sim \ln c$. Furthermore as $T$ decreases, the degree of oligomerization increases and the dependence of $\mu_{1}$ on $c$ becomes weaker. Thus the increase of $\mu_{1}$ from $c^{\mathrm{eq}}(T)$ to $c$, i.e., $\Delta \mu_{1}$, can be very small at low temperatures and can account for the observed minimum of $t_{\text {ind }}$ (see Appendix for a simple quantitative model that includes oligomerization). We also observe that since the degree of oligomerization increases with $c$, the effect of oligomerization on $\Delta \mu_{1}$ is greater at higher concentrations. This observation is consistent with the experimental evidence that the temperature where the minimum occurs increases with $C$ (see Figure 5). In our approximation $\mu_{1} \sim \ln c_{1}$ we have neglected excluded volume interactions. These interactions can be significant at high protein volume fractions. However, on lowering the temperature at constant $c$, the excluded volume contribution to $\Delta \mu_{1}$ is expected to monotonically increase and cannot account for the observed minimum.

If, within domain II of Figure 3, we now move toward phase boundary $\beta$, we can see from Figure 5 that $\log t_{\text {ind }}$ becomes nearly independent of protein concentration near phase boundary $\beta$ and for $C \gtrsim 50 \mathrm{mg} / \mathrm{mL}$. From eq $5 \mathrm{a}-\mathrm{c}$ we realize that this finding is again consistent with a weak dependence of $\mu_{1}$ on $c$. Interestingly, the condition $\left(\partial \mu_{1} / \partial c\right)_{T}$ $=0$ applies along a spinodal boundary (43). Since this boundary is located at temperatures below the binodal boundary (i.e., phase boundary $\beta$ ), the observed small change of $\log t_{\text {ind }}$ with $C$ at low temperatures suggests that, for $C \gtrsim$ $50 \mathrm{mg} / \mathrm{mL}$ and $T=6{ }^{\circ} \mathrm{C}$, the spinodal boundary, $T_{\mathrm{sp}}(C)$, lies close to the binodal boundary, $T_{\mathrm{ph}}(C)$. We can approximately estimate the position of $T_{\mathrm{sp}}(C)$ relative to $T_{\mathrm{ph}}(C)$ by using mean-field theory (43). Within this approximation, $T_{\mathrm{c}}-T_{\mathrm{sp}} \approx 3\left(T_{\mathrm{c}}-T_{\mathrm{ph}}\right)$. This relationship has been shown to well represent the difference between $T_{\mathrm{ph}}(C)$ and $T_{\mathrm{sp}}(C)$ for $\gamma \mathrm{B}$-crystallin (24). Using our values for $T_{\mathrm{ph}}(C)$ and $T_{\mathrm{c}}=6.4{ }^{\circ} \mathrm{C}$ (see Figure 3), we estimated that $T_{\mathrm{ph}}$ $-T_{\mathrm{sp}} \approx 3{ }^{\circ} \mathrm{C}$ at $C=50 \mathrm{mg} / \mathrm{mL}$. This difference decreases to $T_{\mathrm{ph}}-T_{\mathrm{sp}} \approx 1^{\circ} \mathrm{C}$ at $C=100 \mathrm{mg} / \mathrm{mL}$ and becomes smaller at the higher protein concentrations of Figure 5. Thus, our mean-field estimates of the spinodal boundary position predict that $T_{\mathrm{sp}}(C)$ lies close to $T_{\mathrm{ph}}(C)$ and is consistent with the observed behavior of $\log t_{\text {ind }}$. This relation between $T_{\mathrm{sp}}(C)$ and $T_{\mathrm{ph}}(C)$ can be used also to explain the sharp increase of the turbidity time $t_{\tau=1}$ in Figure 8 for $C>50$ $\mathrm{mg} / \mathrm{mL}$ and $T=1.0^{\circ} \mathrm{C}$. We have estimated that $T_{\mathrm{sp}} \approx 1{ }^{\circ} \mathrm{C}$ at $C=50 \mathrm{mg} / \mathrm{mL}$. This implies that the large values of $t_{t=1}$ (with $C>50 \mathrm{mg} / \mathrm{mL}$ ) were measured inside the spinodal domain, where phase separation occurs through the formation of the bicontinuous network discussed in the previous section.

\section{SUMMARY AND CONCLUSIONS}

We have investigated the phenomena of oligomerization and phase separation in aqueous solutions of native $\beta \mathrm{B} 1$ and its truncated form $\beta \mathrm{B} 1 \Delta \mathrm{N} 41$. These studies have allowed us to (1) determine the role of truncation on both oligomerization and phase separation of $\beta \mathrm{B} 1$, (2) compare the phase behavior for $\beta \mathrm{B} 1$ with that of the well-characterized $\gamma$-crystallin systems, and (3) gain insight on general phase behavior of protein aqueous solutions in the presence of reversible oligomerization.

The oligomerization studies show that the energy of attraction between the $\beta \mathrm{B} 1 \Delta \mathrm{N} 41$ proteins is about $10 \%$ greater than that of $\beta \mathrm{B} 1$. Furthermore, this energy of attraction is 1 order of magnitude greater than the weak energy of attraction found in the case of $\gamma$-crystallins.

We note that protein crystallization was observed only in the case of the truncated protein, suggesting that the removal of the $\mathrm{N}$-terminal arm permits crystallization. We have shown that the kinetic evolution of $\beta \mathrm{B} 1 \Delta \mathrm{N} 41$ crystallization is determined by both the phenomenon of oligomerization and the proximity of the LLPS boundary. These results show that the rate of protein crystallization is reduced by the presence of associative processes in solution and the presence of other phase transitions.

For both $\beta \mathrm{B} 1$ and $\beta \mathrm{B} 1 \Delta \mathrm{N} 41$, we have shown that oligomerization increases as the temperature is lowered. As the temperature is lowered sufficiently, we observe heterogeneous gelation. We find that heterogeneous gelation differs from a regular liquid-liquid phase transition, such as the one observed in the case of $\gamma$-crystallins, because it is the result of LLPS accompanied by association and gelation within the protein-rich phase. For truncated $\beta \mathrm{B} 1 \Delta \mathrm{N} 41$, the temperature of heterogeneous gelation is higher than that found for native $\beta \mathrm{B} 1$. The increase in critical temperature from the $\beta \mathrm{B} 1$ case to the $\beta \mathrm{B} 1 \Delta \mathrm{N} 41$ case correlates with the corresponding increase in the magnitude of the oligomerization energy.

The findings described above imply that the $\mathrm{N}$-terminus in the native $\beta \mathrm{B} 1$, which is extended outside the globular 
domain of the protein, suppresses oligomerization and LLPS and prevents protein crystallization.

The ability of native $\beta \mathrm{B} 1$ to suppress association and phase separation is consistent with the maintenance of eye-lens transparency. Conversely, the truncation of the inhibitory arm favors protein condensation and the formation of light scattering elements. Our studies on both native $\beta \mathrm{B} 1$ and truncated $\beta \mathrm{B} 1 \Delta \mathrm{N} 41$ provide the basis for undertaking two further investigations. The first is to determine how intermediate (occurring in vivo) degrees of truncation affect oligomerization and phase separation. Indeed, such an investigation may reveal a crucial determining role for specific amino acids. The second investigation is the study of multicomponent mixtures of $\beta$-crystallins so as to more accurately produce and mimic the $\beta$-crystallin heterooligomers found in the living lens. Here two issues come to the fore. The first is to determine whether the N-terminal arm of $\beta \mathrm{B} 1$ actually facilitates hetero-oligomerization as has been suggested $(8,21,22)$. The second is to determine how hetero-oligomerization affects the phase behavior of the multicomponent $\beta$-crystallin mixtures. Indeed, previous workers have suggested that hetero-oligomers have repulsive interactions (11). If this is the case, hetero-oligomerization could suppress phase separation.

\section{ACKNOWLEDGMENT}

We are very grateful to Aleksey Lomakin for providing valuable guidance in QLS measurements. We also thank Neer Asherie for critical comments and useful discussions.

\section{APPENDIX}

Protein Chemical Potential in the Presence of Oligomerization. Protein dimers reversibly associate to form oligomers in solution. We can write the following reaction scheme for this associative process:

$$
\begin{gathered}
\mathrm{P}+\mathrm{P} \rightleftarrows \mathrm{P}_{2} \\
\mathrm{P}_{2}+\mathrm{P} \rightleftarrows \mathrm{P}_{3} \\
\mathrm{P}_{i-1}+\mathrm{P} \rightleftarrows \mathrm{P}_{i}
\end{gathered}
$$

where $\mathrm{P}$ symbolizes the protein dimer and $\mathrm{P}_{i}$ (with $i=2,3$, ...) symbolizes the higher order oligomers. With each reaction, we can associate a condition of chemical equilibrium, $\mu_{i}=i \mu_{1}$, by considering the chemical potential $\mu_{1}$ for the free protein dimer and $\mu_{i}$ for each oligomer $i$. It is important to observe that $\mu_{1}$ is not only the chemical potential of the protein free dimer species but also the chemical

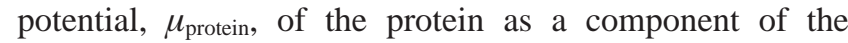
protein-water binary system with total molar concentration $c=\sum_{i=1}^{\infty} i c_{i}$. This can be easily recognized by applying the conditions of chemical equilibrium between the oligomers to the free energy change: $\sum_{i} \mu_{i} \mathrm{~d} c_{i}=\mu_{1} \sum_{i} i \mathrm{~d} c_{i}=\mu_{1} \mathrm{~d} c=$ $\mu_{\text {protein }} \mathrm{d} c$.

In the low protein concentration limit, we can approximate the chemical potentials by $\mu_{i}=\mu_{i}{ }^{\mathrm{O}}+R T \ln \left(c_{i} / c_{i}{ }^{\mathrm{o}}\right)$, where $c_{i}$ the molar concentration of species $i, \mu_{i}{ }^{0}$ is the chemical potential of oligomer $i$ in the standard state at $c_{i}{ }^{\mathrm{O}}=c^{\mathrm{o}}=1$ $\mathrm{M}$, and $R$ is the ideal gas constant.
Using the condition of chemical equilibrium, we can write

$$
\begin{gathered}
K_{i}=\frac{c_{i}}{c_{1} c_{i-1}} \\
\Delta G_{i}^{\mathrm{o}}=\mu_{i}^{\mathrm{o}}-\left(\mu_{i-1}{ }^{\mathrm{o}}+\mu_{1}^{\mathrm{o}}\right)=-R T \ln \left(K_{i} c^{\mathrm{o}}\right)
\end{gathered}
$$

where $K_{i}$ and $\Delta G_{i}{ }^{\mathrm{o}}$ are respectively the equilibrium constant and the standard free energy change associated with the formation of $\mathrm{P}_{i}$ from $\mathrm{P}$ and $\mathrm{P}_{i-1}$.

Diffusion in the Presence of Oligomerization. If the lifetime of the individual species, $\mathrm{P}$ and $\mathrm{P}_{i}$, is long compared to relaxation time for concentration fluctuations, the population of each species is retained during this relaxation time. Thus, the QLS value of $D$ will be the weighted average of the individual diffusion coefficients $D_{1}$ of $\mathrm{P}$ and $D_{i}$ of $\mathrm{P}_{i}$, where the weighting factors are the relative intensities of light scattered by each species. We can write

$$
D=\sum_{i=1}^{\infty} i^{2} c_{i} D_{i} / \sum_{i=1}^{\infty} i^{2} c_{i}
$$

Even in the opposite extreme, that is, when the lifetime of the individual species is short compared to the relaxation time for concentration fluctuations, eq A3 still holds (34).

In eq A3, the molar concentration of the individual species, each $c_{i}$, can be expressed as a function of the total molar concentration, $c$. This can be carried out if it is remembered that each $c_{i}$ is related to $c_{1}$ by the recursion relation: $c_{i}=$ $\left(\prod_{n=2}^{i} K_{n}\right) c_{1}{ }^{i}$. Thus it suffices to obtain $c_{1}(c)$. This is achieved by first expressing $c_{1}(c)$ as a Taylor's expansion in $c$ about $c=0$, viz., $c_{1}=\sum_{n=0}^{\infty}(1 / n !)\left(\mathrm{d}^{n} c_{1} / \mathrm{d} c^{n}\right)_{c=0} c^{n}$. The coefficients in this expansion can be determined from the mass conservation condition: $c=\sum_{i=1}^{\infty} i c_{i}$ and the recursion relation by differentiation. The result for $c_{1}(c)$ is $c_{1}=c-$ $2 K_{2} c^{2}+\left(8 K_{3}^{2}-3 K_{2} K_{3}\right) c^{3}+\ldots$. We apply this result to eq A3 in order to express $D$ as a power series in $c$. Retaining only linear terms in $c$, which corresponds to including only the $\mathrm{P}+\mathrm{P} \rightleftarrows \mathrm{P}_{2}$ equilibrium and neglecting higher order association, we find that $D_{1} / D$ is given by eq 1 , where $R_{\mathrm{h}}{ }^{\mathrm{o}}$ $=k_{\mathrm{B}} T / 6 \pi \eta D_{1}, R_{\mathrm{h}}{ }^{\text {app }}=k_{B} T / 6 \pi \eta D$, and $s \equiv D_{2} / D_{1}$.

Induction Time in the Presence of Oligomerization. To obtain the dependence of $T \Delta \mu_{1}{ }^{2}$ on $T$ and $c$, we need an expression for the thermodynamic supersaturation $\Delta \mu_{1}$. Without loss of generality, the protein chemical potential, $\mu_{1}$, can be expressed in the following way:

$$
\begin{aligned}
\mu_{\text {protein }}(T, c)= & \mu_{1}(T, c)= \\
& \mu_{1}^{\mathrm{o}}(T)+R T \ln \left(c / c^{\mathrm{o}}\right)+R T \ln y(T, c)
\end{aligned}
$$

where $y(T, c)$ is the thermodynamic activity coefficient. By use of eqs $3 c$ and B1, we can write

$$
\Delta \mu_{1}=R T \ln \left(c / c^{\mathrm{eq}}\right)+R T \ln \left(y / y^{\mathrm{eq}}\right)
$$

where $y^{\mathrm{eq}} \equiv y\left[T, c^{\mathrm{eq}}(T)\right]$. We now consider the dependence of $T \Delta \mu_{1}^{2}$ on temperature along a path at constant $c$, moving inside domain II. The presence of a minimum in $t_{\text {ind }}$ implies a maximum in $T \Delta \mu_{1}{ }^{2}$. A maximum in $T \Delta \mu_{1}^{2}$ occurs when $\left[\partial\left(T \Delta \mu_{1}^{2}\right) / \partial T\right]_{c}=0$. Using this condition, we find that the 
temperature, $T_{\mathrm{m}}$, where the maximum occurs is $T_{\mathrm{m}}=$ $-(1 / 2) \Delta \mu_{1} /\left(\partial \Delta \mu_{1} / \partial T\right)_{c}$. Thus, $T_{\mathrm{m}}$ can be directly determined from $\Delta \mu_{1}(T, c)$.

Due to chemical equilibrium among the oligomers, we set the activity coefficient $y$ equal to the fraction of free protein dimers, $y=c_{1}(T, c) / c$, so that eq $\mathrm{B} 2$ gives

$$
\Delta \mu_{1}=R T \ln \left(c_{1} / c_{1}{ }^{\mathrm{eq}}\right)
$$

where $c_{1}^{\mathrm{eq}} \equiv c_{1}\left[T, c^{\mathrm{eq}}(T)\right]$.

We now present a simple model that includes the reversible oligomerization, to provide an explicit expression for $y$ as a function of $T$ and $c$, and show how $T_{\mathrm{m}}$ can be affected by oligomerization. Here we consider the simple case for which the association constants are all equal: i.e., $K_{i}(T)=K(T)$. In this case, by successive applications of eq A1 it follows that $K c_{i}=\left(K c_{1}\right)^{i}$ and

$$
\begin{gathered}
c=\sum_{i=1}^{\infty} i c_{i}=\frac{c_{1}}{\left(1-K c_{1}\right)^{2}} \\
y=\frac{c_{1}}{c}=\frac{2 K c+1-(1+4 K c)^{1 / 2}}{2(K c)^{2}}
\end{gathered}
$$

where eq B4 is obtained by solving for $c_{1}$ as a function of $c$ from eq B3 $(41,42)$.

If we use eq B4 in eq B2, we have an explicit representation of $\Delta \mu_{1}$ as a function of $T$ and $c$ since $K$ is known as a function of $T$ from the data for $\beta \mathrm{B} 1 \Delta \mathrm{N} 41$ in Figure 10. Using eq B4 in eq B2, we now find that there is a maximum in the temperature dependence of $T \Delta \mu_{1}{ }^{2}$ within our experimental domain. The predicted temperature, $T_{\mathrm{m}}$, for which the maximum occurs is $9{ }^{\circ} \mathrm{C}$ at $C=30 \mathrm{mg} / \mathrm{mL}$ and rises to 13 ${ }^{\circ} \mathrm{C}$ at $280 \mathrm{mg} / \mathrm{mL}$. The corresponding experimental value of $T_{\mathrm{m}}$ is $13{ }^{\circ} \mathrm{C}$ at $C=30 \mathrm{mg} / \mathrm{mL}$ and rises to $21^{\circ} \mathrm{C}$ at 280 $\mathrm{mg} / \mathrm{mL}$. Thus, our model is able to show the experimentally observed increase of $T_{\mathrm{m}}$ with protein concentration. The numerical difference between the experimental and predicted values of $T_{\mathrm{m}}$ can be regarded as acceptable considering the great simplifications inherent in the assumptions underlying eqs $3 \mathrm{a}-\mathrm{c}$ and $\mathrm{B} 4$.

\section{REFERENCES}

1. Benedek, G. B. (1997) Cataract as a protein condensation disease: the Proctor Lecture, Invest. Ophthalmol. Vis. Sci. 38, 1911-1921.

2. Delaye, M., and Tardieu, A. (1983) Short-range order of crystallin proteins accounts for eye lens transparency, Nature 302, 415417.

3. Wistow, G. J., and Piatigorsky, J. (1988) Lens crystallins: the evolution and expression of proteins for a highly specialized tissue, Annu. Rev. Biochem. 57, 479-504.

4. Lubsen, N. H., Aarts, H. J. M., and Schoenmakers, J. G. G. (1988) The evolution of lenticular proteins: the $\beta$ - and $\gamma$-crystallin super gene family, Prog. Biophys. Mol. Biol. 51, 47-76.

5. Lampi, K. J., Ma, Z., Shih, M., Shearer, T. R., Smith, J. B., Smith, D. L., and David, L. L. (1997) Sequence analysis of $\beta$ A3, $\beta$ B3, and $\beta \mathrm{A} 4$ crystallins completes the identification of the major proteins in young human lens, J. Biol. Chem. 272, 2268-2275.

6. David, L. L., Lampi, K. J., Lund, A. L., and Smith, J. B. (1996) The Sequence of Human $\beta \mathrm{B} 1$-crystallin cDNA allows mass spectrometric detection of $\beta \mathrm{B} 1$ protein missing portions of its N-terminal extension, J. Biol. Chem. 271, 4273-4279.
7. Miesbauer, L. R., Smith, J. B., and Smith, D. L. (1993) Amino acid sequence of human lens $\beta$ B2-crystallin, Protein Sci. 2, 290291.

8. Ajaz, M. S., Ma, Z., Smith, D. L., and Smith, J. B. (1997) Size of human lens $\beta$-crystallin aggregates are distinguished by $\mathrm{N}$-terminal truncation of $\beta \mathrm{B} 1, \mathrm{~J}$. Biol. Chem. 272, 11250-11255.

9. Ma, Z., Hanson, S. R. A., Lampi, K. J., David, L. L., Smith, D. L., and Smith, J. B. (1998) Age-related changes in human lens crystallins identified by HPLC and mass spectrometry, Exp. Eye Res. 67, 21-30.

10. Bateman, O. A., Lubsen, N. H., and Slingsby, C. (2001) Association behaviour of human $\beta \mathrm{B} 1$-crystallin and its truncated forms, Exp. Eye Res. 73, 321-331.

11. Tardieu, A., Vérétout, F., Krop, B., and Sligsby, C. (1992) Protein interactions in the calf eye lens: interactions between $\beta$-crystallins are repulsive whereas in $\gamma$-crystallins they are attractive, Eur. Biophys. J. 21, 1-12.

12. Zhang, Z., Ma, Z., Smith, D. L., and Smith, J. B. (2003) Human $\beta$-crystallins modified by backbone cleavage, deamidation and oxidation are prone to associate, Exp. Eye Res. 77, 259-272.

13. van Monfort, R. L. M., Bateman, O. A., Lubsen, N. H., and Slingsby, C. (2003) Crystal structure of truncated human $\beta$ B1crystallin, Protein Sci. 12, 2606-2612.

14. Bax, B., Lapatto, R., Nalini, V., Driessen, H. P. C., Lindley, P. F., Mahadevan, D., Blundell, T. L., and Slingsby, C. (1990) X-ray analysis of $\beta \mathrm{B} 2$-crystallin and evolution of oligomeric lens proteins, Nature 347, 776-780.

15. Najmudin, S., Nalini, V., Driessen, H. P. C., Slingsby, C., Blundell, T. L., Moss, D. S., and Lindley, P. F. (1990) Structure of the bovine eye lens protein $\gamma \mathrm{B}(\gamma \mathrm{II})$-crystallin at $1.47 \AA$, Acta Crystallogr. D 49, 223-233.

16. Fine, B. M., Lomakin, A., Ogun, O., and Benedek, G. B. (1996) Static structure factor and collective diffusion of globular proteins in concentrated aqueous solution, J. Chem. Phys. 104, 326-335.

17. Liu, C., Pande, J., Lomakin, A., Ogun, O., and Benedek, G. B. (1998) Aggregation in aqueous solutions of bovine lens $\gamma$-crystallins: special role of $\gamma \mathrm{S}$, Invest. Ophthalmol. Visual Sci. $39,1609-1619$.

18. Hejtmancik, J. F., Wingfield, P. T., Chambers, C., Russel, P., Chen, H. C., Sergeev, Y. V., and Hope, J. N. (1997) Association properties of $\beta \mathrm{B} 2-$ and $\beta \mathrm{A} 3$-crystallin: ability to form dimers, Protein Eng. 10, 1347-1352.

19. Lampi, K. J., Oxford, J. T., Bachinger, H. P., Shearer, T. R., David, L. L., and Kapfer, D. M. (2001) Deamidation of human $\beta$ B1 alters the elongated structure of the dimer, Exp. Eye Res. 72, 279-288.

20. Lampi, K. J., Ma, Z., Hanson, S. R. A., Azuma, M., Shih, M., Shearer, T. R., Smith, D. L., Smith, J. B., and David, L. L. (1998) Age-related changes in human lens crystallins identified by twodimensional electrophoresis, Exp. Eye Res. 67, 31-43.

21. Werten, P. L. J., Lindner, R. A., Carver, J. A., and de Jong, W W. (1999) Formation of $\beta \mathrm{A} 3 / \beta \mathrm{B} 2$-crystallin mixed complexes: involvement of N- and C-terminal extensions, Biochim. Biophys. Acta, Protein Struct. M 1432, 286-292.

22. Bateman, O. A., Sarra, R., van Genesen, S. T., Kappé, G., Lubsen, N. H., and Slingsby, C. (2003) The stability of human acidic $\beta$-crystallin oligomers and hetero-oligomers, Exp. Eye. Res. 77, 409-422.

23. Kim, Y. H., Kapfer, D. M., Boekhorst, J., Lubsen, N. H., Bächinger, H. P., Shearer, T. R., David, L. L., Feix, J. B., and Lampi, K. J. (2002) Deamidation, but not truncation, decreases the urea stability of a lens structural protein, $\beta \mathrm{B} 1$-Crystallin, Biochemistry 41, 14076-14084.

24. Thomson, J. A., Schurtenberger, P., Thurston, G. M., Thomson, J. A., and Benedek, G. B. (1987) Binary liquid-phase separation and critical phenomena in a protein-water solution, Proc. Natl. Acad. Sci. U.S.A. 84, 7079-7083.

25. Broide, M. L., Berland, C. R., Pande, J., Ogun, O., and Benedek, G. B. (1991) Binary-liquid phase separation of lens protein solutions, Proc. Natl. Acad. Sci. U.S.A. 88, 5660-5664.

26. Lomakin, A., Asherie, N., and Benedek, G. B. (1996) Monte Carlo study of phase separation in aqueous protein solutions, J. Chem. Phys. 104, 1646-1656.

27. Asherie, N., Lomakin, A., and Benedek, G. B. (1998) Phase diagram of colloidal solutions, Phys. Rev. Lett. 77, 4832-4835.

28. Lomakin, A., Asherie, N., and Benedek, G. B. (1999) Aeolotopic interactions of globular proteins, Proc. Natl. Acad. Sci. U.S.A. 96, 9465-9468. 
29. Liu, C., Asherie, N., Lomakin, A., Pande, J., Ogun, O., and Benedek, G. B. (1996) Phase separation in aqueous solutions of lens $\gamma$-crystallins: special role of $\gamma \mathrm{S}$, Proc. Natl. Acad. Sci. U.S.A. 93, 377-382

30. Annunziata, O., Ogun, O., and Benedek, G. B. (2003) Observation of liquid-liquid phase separation for eye lens $\gamma \mathrm{S}$ crystallin, Proc. Natl. Acad. Sci. U.S.A. 100, 970-974.

31. Asherie, N., Pande, J., Lomakin, A., Ogun, O., Hanson, S. R. A., Smith, J. B., and Benedek, G. B. (1998) Oligomerization and phase separation in globular protein solutions, Biophys. Chem. 75, 213227.

32. van Holde, K. E. (1971) Physical Biochemistry, 2nd ed., Prentice Hall, Englewood Cliffs, NJ.

33. Annunziata, O., Asherie, N., Lomakin, A., Pande, J., Ogun, O., and Benedek, G. B. (2002) Effect of poly(ethylene glycol) on the liquid-liquid phase transition in aqueous protein solutions, Proc. Natl. Acad. Sci. U.S.A. 99, 14165-14170.

34. Berne, B. J., and Pecora, R. (1976) Dynamic Light Scattering with Applications to Chemistry, Biology and Physics, Wiley, New York.

35. García de la Torre, J., and Bloomfield, V. A. (1981) Hydrodynamic properties of complex, rigid, biological macromolecules, $Q$. Rev. Biophys. 14, 81-139.
36. Kern, N., and Frenkel, D. (2003) Fluid-fluid coexistence in colloidal systems with short-ranged strongly directional attraction, J. Chem. Phys. 118, 9882-9889.

37. Kashchiev, D. (2000) Nucleation: Basic Theory with Applications, Butterworth-Heinemann, Oxford, U.K.

38. Mullin, J. W. (2001) Crystallization, 4th ed., ButterworthHeinemann, Oxford, U.K.

39. Galkin, O., and Vekilov, P. G. (2001) Nucleation of protein crystals: critical nuclei, phase behavior, and control pathways, $J$. Crystal Growth 232, 63-76.

40. Eisenberg, D., and Crothers, D. (1979) Physical Chemistry with Applications to the Life Science, Benjamin-Cummings, Menlo Park, CA.

41. Cohen, R. J., and Benedek, G. B. (1982) Equilibrium and kinetic theory of polymerization and the sol-gel transition, J. Phys. Chem. $86,3696-3714$.

42. Oosawa, F., and Asakura, S. (1975) Thermodynamics of the Polymerization of Protein, Academic Press, London.

43. Stanley, H. E. (1971) Introduction to Phase Transitions and Critical Phenomena, North-Holland, New York.

BI048419F 